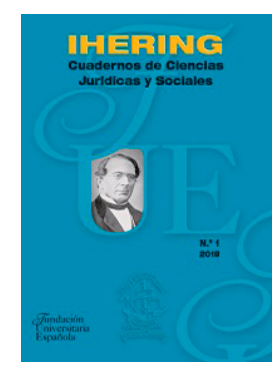

\author{
Ihering. Cuadernos de Ciencias Jurídicas y Sociales \\ $\mathrm{N}^{\mathrm{o}} 2$
}

Año: 2019

e-issn: 2660-552X

DOI: https://doi.org/10.51743/ihering. 17

(c) $\underset{\mathrm{EY}}{(\mathrm{i})}$

\title{
La existencia de una competencia real en la oferta de servicios universitarios en España
}

\author{
The presence of true competition \\ in university accademic offering in Spain
}

\author{
FERNANDO LOSTAO CRESPO
}

Doctorando CEINDO- Programa de Derecho y Economía- . Escuela Internacional Doctorado CEU

\begin{abstract}
Resumen
Universidades públicas y privadas compiten en España por el mismo mercado con unas reglas de juego muy distintas, ya que las públicas tienen financiación directa de sus costes aproximadamente en un $75 \%$. Esta financiación no tiene la consideración de ayudas públicas prohibidas para el derecho europeo, dado que la educación subvencionada en la UE entra en la categoría de Servicio No Económico de Interés General. Sin embargo, y a sensu contrario, la educación pagada por el alumno, si es un Servicio Económico, al que, por lo tanto, debería aplicarse toda la normativa que tiene por objeto facilitar la prestación de los mismos, en donde el principio de autorización tendría que tener un carácter subsidiario. Pero muy al contrario, la legislación española, en especial la autonómica, está plagada de procedimiento de autorización, que limitan de modo artificial el desarrollo de las universidades privadas, conteniendo algunos de ellos requisitos expresamente prohibidos.

Además, el sistema de financiación de la universidad en España es poco equitativo, poco eficiente, y no ayuda a la promoción de la competencia interna, permitiendo además que se den situaciones de abuso de posición de dominio, al utilizar las universidades
\end{abstract}


públicas la financiación para fines distintos a la enseñanza e investigación oficial. En contraste, tenemos otros sistemas universitarios, como el británico, que financia directamente a los alumnos en forma de préstamos, que sólo deben comenzarse a devolver cuando los alumnos alcanzan un determinado nivel de ingresos.

\begin{abstract}
Public and private Universities in Spain compete for the same market under very different sets of rules. Public Universities have approximately $75 \%$ of their cost financed. Their financing is not considered as public aid which is non-compliant with European law given that subsidized education in the $\mathrm{EU}$ is considered to be a Non-Economic Service of Public Interest. However, a sensu contrario, education paid by the student is considered to be an Economic Service. Regulation aimed at facilitating paid Education provision applies and principles for authorisation should establish that only be requested as an exception. Quite the contrary, Spanish and especially regional governments' legislation requires too many authorization procedures that restrict in a non-organic way the development of private Universities. Some of these procedures contain requirements expressly forbidden by law.

In addition, Spanish University financing system is unfair, inefficient and does not foster competition allowing situations of abuse of dominant position when public universities use financing for purposes other than official teaching and research. On the contrary, there are other university systems, such as the British system, which directly finances students in the form of loans and establishes its repayment to start only once students reach a certain level of income.
\end{abstract}

\title{
Palabras clave
}

(ES) Universidad, pública, privada, financiación, servicio, económico, competencia.

\section{Key words}

(EN) University, public, private, funding, service, economic, competition.

\section{Contenidos}

(ES) I. Ausencia de modelo legal. II. Los elementos que distorsionan la competencia en el mercado universitario. III. Panorama clasificatorio de la universidad española. IV. Situación de la universidad pública. V. Legalidad y eficiencia de la financiación de la universidad pública española. A. La legalidad de partida del sistema de financiación de la universidad pública española. B. Posible abuso de posición de dominio. 
C. Defectos del sistema de financiación. 1. Falta de equidad. 1.1. Precios públicos altamente subvencionados de partida. 1.2. Los beneficios de los títulos universitarios. 1.3. Inequidad territorial. 2. Falta de eficiencia. 2.1 Falta de información de costes reales. 3. Financiación no pro competitiva. VI. Régimen jurídico de la prestación de servicios económicos en territorio de la unión europea. A. Principios. B. Criterios autorizatorios prohibidos para la administración. VII. La realidad: maraña de autorizaciones. A. Nacimiento de la universidad y normas de funcionamiento. B. Control de las normas de organización y funcionamiento. C. autorización autonómica del inicio de actividades. D. Puesta en funcionamiento de una titulación. E. Más autorizaciones necesarias. F. Modificación de los planes de estudio. VIII. Requisitos prohibidos en la normativa autonómica. A. De naturaleza económica. B. Programación universitaria. C. Prohibición absoluta de duplicidad de titulaciones, en particular el caso de Aragón. D. La exigencia de un número mínimo de alumnos. E. Limitaciones específicas en la CA de Valencia F. Otras limitaciones. IX. Conclusiones.

\section{Contents}

(EN) I. Absence of legal model. II. Elements that distort competition in the university market. III. Spanish university's rating panorama. IV. Public university's situation. V. Legality and efficiency of Spanish public university financing. A. The question of legality as a starting point for the financing system of Spanish public university. B. Possible dominant position abuse. C. Financing system defects. 1. Lack of equity. 1.1. Highly subsidized public prices as starting point. 1.2. Benefits of university certifications. 1.3. Territorial inequity. 2. Lack of efficiency. 2.1 Lack of information on real costs. 3. Non pro-competitive financing. VI. Legal framework for the provision of economic services in the European Union territory. A. Principles. B. Authorizing criteria forbidden for the government. VII. Reality: Authorizations' tangle. A. The university's birth, policies and procedures. B. Organization and procedures policy management. C. Regional government's authorization for activities initiation. D. University degree programme commissioning. E. Other authorizations required. F. Programmes' modifications. VIII. Regional policy's requirements forbidden by law A. Of an economic nature. B. University Programming C. Absolute prohibition of degrees' duplication and Aragón' particular case. D. The requirement for a minimum number of students. E. Specific limitations in Valencia's Regional Government. F. Other limitations. IX. Conclusions. 


\section{AUSENCIA DE MODELO LEGAL.}

T a legislación española carece por completo de un modelo, de unas categorías jurídicas, o de razonamiento alguno, que justifiquen mínimamente el trato tan diferente entre las universidades privadas y públicas. La vigente Ley Orgánica de Universidades (LOU) de 2001 se limita a recoger la existencia de las privadas, y a regular algunos aspectos de su funcionamiento, además de modo bastante mejorable, pero nada más, no realiza ningún razonamiento que justifique un trato financiero público tan desigual.

Como decimos la distinción legal que hace la LOU entre universidades públicas y privadas podría calificarse de ridícula por inexistente: el art. $3^{1}$ de esta norma viene a decir que las universidades públicas son las que son públicas, y las privadas las demás. Más específicamente, sí que se establece una pequeña distinción: son públicas las universidades creadas, y privadas las reconocidas; no hay más distinción, ya que los órganos legislativos que las deben crear o reconocer son los mismos, y sus funciones - cuestión esencial -, son exactamente las mismas. No existe normativamente nada que justifique un régimen tan distinto. El preámbulo de la LOU, en el segundo párrafo del apartado II, se limita a indicar que su existencia se debe a la necesidad de recoger el derecho a la creación de centros de enseñanza contemplado en la Constitución, y que se les someterá a las mismas exigencias que a las públicas. Es decir, reconocimiento constitucional, mismas funciones, iguales exigencias, pero tratamiento económico totalmente distinto. El otro apartado del preámbulo de la LOU que menciona a las universidades privadas es el IV, en el que se limita a señalar la pertenencia de las Universidades Privadas al Consejo de Universidades salvo cuando se

\footnotetext{
${ }^{1}$ Artículo 3. Naturaleza.

1. Son Universidades públicas las instituciones creadas por los órganos legislativos a que se refiere el apartado 1 del artículo 4 y que realicen todas las funciones establecidas en el apartado 2 del artículo 1 .

2. Son Universidades privadas las instituciones no comprendidas en el apartado anterior, reconocidas como tales en los términos de esta Ley y que realicen todas las funciones establecidas en el apartado 2 del artículo 1.
} 
traten cuestiones que afecten sólo a las universidades públicas. Y a partir de ahí el título IX -arts. 79 a 85-, que regula el Régimen Económico y Financiero de las Universidades Públicas, y que comienza proclamando la autonomía económica y financiera, de las Universidades Públicas, en los términos establecidos en la presente Ley.

Tampoco la predecesora de la LOU, la LRU, contenía algúnelemento más aclaratorio, ya que sus referencias a la Universidad Privada, arts. 57 a 59, en cuanto a categoría diferente a las Públicas, era tan limitada como las de la legislación vigente; poco más que una referencia a la libertad o derecho a la libertad de creación de centros docentes como origen de su existencia. El preámbulo de la LRU carecía de referencia alguna.

La preponderancia de lo público en el sistema universitario español nace de la adopción en el siglo XIX ${ }^{2}$ del modelo napoleónico de intervención y publificación de la educación universitaria. Y salvo por algunas excepciones, representadas por Universidades de la Iglesia, que obedecieron a los Conciertos con la Santa Sede de 1953, tampoco el régimen de Franco apostó por la universidad privada.

En medio de esta panorama se desenvuelve la universidad privada en España, tanto las de la Iglesia como las civiles, tratando de marcar una oferta diferenciada, y de ganar cuotas de mercado a un gigante que cuenta con una ventaja competitiva casi insuperable como es la tener sus costes de docencia subvencionados directamente en un $75 \%$ aproximadamente. La normativa de las universidades privadas en España ha llegado tarde y mal. Está llena de lagunas, incoherencias y restricciones. En la práctica es la hermana pobre del sistema universitario español, algo residual, un mal inevitable, y sobrevive, a pesar de que está sometida a las mismas exigencias que las públicas, y ninguna de sus ventajas.

Todo esto está asentado sobre una premisas que nadie se atreve a discutir, cuyo cambio probablemente da terror a los políticos;

\footnotetext{
${ }^{2}$ Siguiendo José Manuel Pérez Prendes Muñoz-Arraco. Aspectos históricos de la ordenación universitaria. Comentarios a la LOU, fue el plan de Gil de Azcárate el que supuso la estatalización de las universidades, su absorción y control financiero, además de su reducción a diez: Barcelona, Granada, Madrid (por traslado de la complutense en 1.836), Oviedo, Salamanca, Santiago, Sevilla, Valencia, Valladolid y Zaragoza
} 
- La enseñanza universitaria, casi como de si una enseñanza básica se tratara debe llegar al alcance de todos, y al menor coste posible.

- Un modelo de gobernanza con un componente participativo/democrático muy elevado, que algunos califican como autogestionario.

- Una alta financiación directa de los costes de la enseñanza de las universidades públicas, frente a una nula financiación de la privada.

Casi nadie se atreve a hablar de cambio del modelo de financiación de la universidad pública, y más en un contexto en el que las universidades públicas están en queja continua sobre los recortes que sufren. Menos aún se atreve a hablar nadie de la financiación directa de las universidades privadas o a sus alumnos, aunque en España existen tramos de educación no obligatoria financiados al sector privado vía concierto, como el Bachillerato o los Ciclos Formativos de Grado Superior.

Pero ha habido voces autorizadas que sí se han atrevido a hablar de incrementar significativamente la financiación directa de las universidades públicas vía incremento de los precios públicos y proporcional de becas. Voces que confluyen con otras que, sobre todo en los años mayor masificación, abogaban por la generación de una universidad más elitista desde el punto de vista intelectual, poniendo el énfasis en que nos encontramos estamos en unos tramos de educación no obligatorio.

\section{LOS ELEMENTOS QUE DISTORSIONAN LA COMPETENCIA EN EL MERCADO UNIVERSITARIO.}

Una cosa es que desde la perspectiva del derecho Europeo no puedan considerarse ilegales las ayudas que reciben las universidades públicas, y otra muy distinta que el sistema de financiación de la universidad pública española sea el ideal para generar una mayor competencia y calidad, y una tercera cuestión es analizar si las ayudas que reciben las universidades públicas se destinan completamente al cumplimiento de los fines que le son propios, o al menos en un porcentaje de las mismas se puede estar haciendo un uso anómalo e incluso abusivo de ellas, que pueda dar lugar a situaciones de abuso de la posición de dominio. 
Además, y este constituirá el otro elemento fundamental objeto de estudio en este artículo, la condición de no subvencionado de los servicios universitarios no públicos, hacen que estos sí que tengan la condición de servicios económicos desde la perspectiva del derecho europeo, y esta circunstancia debería de tener unas importantes consecuencias en orden a las condiciones y requisitos que las administraciones deberían establecer al regular la condiciones de prestación de los mismos por las instituciones privadas de enseñanza. La consecuencia lógica de no obtener financiación pública, y competir contra otra parte del sistema que si lo tiene, debería ser la de no estar sometido a las mismas reglas en orden a la puesta en marcha y desarrollo de sus servicios universitarios, que básicamente son: condiciones de autorización de centros, títulos, e incremento de plazas de nueva entrada. Lo que no debería ser es que una parte del sistema de quede con la parte mala que supone la falta de financiación, y no obtenga la parte buena consistente en una mayor flexibilidad en su desarrollo acorde con la naturaleza económica de sus servicios.

Pero antes de entrar en el análisis de estos elementos que en nuestra opinión distorsionan y limitan la competencia en el sistema universitario español, realizaremos una breve panorámica de la situación de la Universidad Española hoy.

\section{PANORAMA CLASIFICATORIO DE LA UNIVERSIDAD ESPAÑOLA.}

Aunque los ránquines no constituyen una verdad infalible, entre otras cosas porque en el caso de la universidad española, tenemos realidades universidades universitarias muy distintas desde el punto de vistas de los recursos, lo cierto es que aportan una información valiosa de la panorámica mundial.

El conocido como ranquin de Shanghai (Academic Rankin of World Universities) ${ }^{3}$, nos dice que de las 100 mejores universidades del mundo, 67 son de USA, 8 de UK, 5 de Australia, 4 de Alemania, 3 de Canadá y

\footnotetext{
${ }^{3}$ http://www.shanghairanking.com/es/
} 
China, 2 de Suiza, Suecia, Singapur, e Israel, y 1 de Holanda, Finlandia, Noruega y Rusia. España sólo coloca una entre las 200 mejores (Universidad de Barcelona).

Para el QS World University Rankin ${ }^{4}$ de 2018, entre las 50 mejores: 24 son de USA, 12 de UK, 3 de Hong Kong y Australia, 2 Canadá, South Corea y China, y 1 Japón y Francia. España sólo tiene una entre las 200 mejores, la de Barcelona que ocupa el $n^{\circ} 156$, y luego vienen la 233 la de Santiago, y la 270 la de Navarra (la primera privada).

A nivel interno el U-Ranquin ${ }^{5}$ de la Fundación BBVA y el IVIE (Instituto Valenciano de Investigaciones económicas), establece el siguiente ranquin de la universidades españolas: Pompeu Fabra, Carlos III, Politécnica de Cataluña, Politécnica de Valencia, y ex aequo en el $4^{\circ}$ puesto Autónoma de Madrid, Cantabria, Autónoma de Barcelona, Rovira i Virgili, Universidad de Navarra, Miguel Hernández, Politécnica de Madrid, Santiago, Barcelona y Valencia.

En unos ránquines como los mencionados, en los que todo los relativo a los resultados de investigación tienen un gran peso, entre las privadas sólo la Universidad de Navarra destaca mínimamente, sin embargo, si acudimos a otros métodos de clasificación, como pueda ser el de la valoración de la docencia y de otros servicios universitarios, por los propios alumnos vemos que los resultados en los que afecta a las universidades españolas son muy diferentes.

El periódico el Economista publicó el 25 de octubre de $2018^{6}$, bajo la rúbrica de la mejores universidades según los alumnos, los resultados de una encuesta que contaba con 60.000 valoraciones de alumnos sobre aspectos como la docencia, 1 vida extrauniversitaria, la internacionalidad, las salidas laborales, o los servicios complementarios, y los resultados fueron bien distintos a los del U-Ranquin de universidades españolas. Según esta encuesta de las 15 mejores universidades españolas las 7 primeras son privadas, y hasta el puesto 8 no aparece la primera universidad

\footnotetext{
${ }^{4}$ https://www.topuniversities.com/university-rankings/world-university-rankings/2018

${ }_{6}^{5} \mathrm{http}: / /$ www.u-ranking.es/analisis.php

6 https://www.eleconomista.es/ecoaula/noticias/9475511/10/18/Las-mejores-universidadesde-Espana-segun-los-estudiantes.html
} 
pública, la Carlos III, y de las 15 mejores, 10 son privadas, 4 públicas, y $1 \operatorname{mixta}^{7}$ como la Oberta de Cataluña.

Esta mejor realización de la docencia, y prestación de servicios vinculados a ella, ha hecho que de facto la universidad privada vaya poco ganando en cuota de mercado frente a la pública que según la Fundación BBVA en una publicación denominada: Esenciales $N^{o}$ 20: Evolución De La Universidad Privada y Resultados Universitarios de 19 de octubre de $2017^{8}$, entiende que ese porcentaje llega al 16,4\%.

\section{SITUACION DE LA UNIVERSIDAD PUBLICA}

Después de pasados 36 años de la LRU de 1983, y de las advertencias realizadas por muchos expertos e informes oficiales (Bricall en el año 2.000, Tarrach en el $2011^{10}$, y Wert en el $2013^{11}$ ) la universidad pública sigue adoleciendo de los mismos defectos que se vienen reiterando una y otra vez, que por cierto ignoran casi por completo a la privada. El propio Tarrach en una entrevista realiza al periódico El Mundo en febrero de 2017, ya como presidente de las Asociación de Universidades Europeas, reconocía que tanto su

\footnotetext{
${ }^{7}$ Promovida por la un poder público como es la CA de Cataluña, pero de forma jurídico privada.

8 https://www.fbbva.es/noticias/numero-universidades-privadas-se-ha-multiplicado-cinco-20anos-ya-forman-al-164-los-estudiantes/

${ }^{9}$ Informe Universidad 2.000 elaborado por José María Bricall ex rector de la Universidad de Barcelona, para la CRUE, Conferencia de Rectores Españoles. https://www.oei.es/historico/oeivirt/bricall.htm

${ }^{10} \mathrm{El}$ informe denominado Audacia para llegar lejos: universidades fuertes para la España del mañana, fue elaborado por una comisión de expertos presidida por Rolf Tarrach, presidente de la European University Association (EUA), elaborado a petición del Ministro Gabilondo en el año 2011, y dentro de plan denominado estrategia universidad 2015. Contribución de las universidades al progreso socioeconómico español

http://www.usc.es/export9/sites/webinstitucional/gl/web/descargas/informe-finaleu2015.pdf

${ }^{11}$ Informe elaborado en febrero de 2013, por una comisión de expertos a petición del ministro José Ignacio Wert.

http://ccoo.upv.es/files/Debate/2013/2013-02-

12_Universidad_Informe_del_Comite_de_Expertos.pdf
} 
informe como el encargado por el Ministro Wert estaban guardados en algún cajón del Ministerio. ${ }^{12}$

Haremos un breve repaso a lo que algunos autores han dicho. En vísperas a la entrada en vigor de la LOU, Antonio Embid y Francisco Michavila ${ }^{13}$, hacían balance de los casi 20 años de vigencia de la LRU de 1983, y enumeraban los retos de la universidad en el siglo XXI, y que en su opinión deberían ser objeto de un gran pacto:

1. Aumento de la financiación con sustanciales mejoras de las ayudas a los estudiantes vía préstamo, crédito etc.

2. Reforma del sistema de gobierno y modificación de las estructuras organizativas, para hacerlas más flexibles, distinguiendo entre gobierno y la dirección de las universidades, y su gestión, que debe ser profesionalizada.

3. Implantación de un sistema nítido de rendimiento de cuentas e incentivos, basado en los resultados de los programas de evaluación.

4. Cambio del sistema de selección del profesorado y mayor preocupación por su formación, mediante el desarrollo de programas a largo plazo, que se ocupen de la introducción de metodologías docentes innovadoras y refuerce la misión pedagógica.

También antes de la entrada en vigor de la LOU, José Ramón Chaves García entendía no podía negarse la oportunidad de acometer esta reforma. "El sistema universitario español estaba zarandeado por los vientos externos de la Unión Europea y la idea le competitividad, y por lo remolinos internos generados por modelos de organización agotado y con graves disfunciones. Junto a ello arreciaba el clamor social frente a los casos de endogamia, situaciones de despilfarro presupuestario, abuso de autonomía". ${ }^{14}$

\footnotetext{
${ }^{12} \mathrm{https} / / /$ www.elmundo.es/f5/campus/2017/02/08/589a03c122601dc2608b463a.htm

${ }^{13}$ Hacia una nueva Universidad. Apuntes para un debate. Tecnos 2001

${ }^{14}$ La Universidad Pública al derecho y al revés. Guergráfica, 2002.
} 
Para el profesor José Luis Martínez López Múñiz ${ }^{15}$ la causa principal de los males que aquejan a la Universidad española, "lo constituye un grave error arrastrado desde hace años por todo el sistema universitario consistente en la instalada confusión entre autonomía universitaria y autogestión por una comunidad universitaria". ${ }^{16}$

En el año 2013, el informe Wert, que como dice Tarrach, también se ha quedado olvidado en algún cajón del ministerio, realizaba propuestas dirigidas a evitar la endogamia, transitar hacia la desfuncionarización, gobernanza mucho más flexible a través de la creación del nuevo Consejo de Universidad, mezcla de los actuales Consejos de Gobierno y Consejos Económicos y Sociales, mejora de la financiación, y menor burocratización en general.

Como hemos dicho, después de pasados 36 años de la LRU de 1983, y 18 de la LOU, la universidad pública sigue adoleciendo casi de los mismos defectos, y a pesar de todo lo dicho, casi ninguna mejora se introduce en la universidad en cuanto a organización, cuestión distinta claro está, son los muchos méritos de docentes e investigadores, ya sea a nivel individual, o como parte de un grupos de investigación. Una cosa es que la universidad pública sea muy mejorable como organización, y otra muy distinta la calidad de su PDI. Pero como organización, todo sigue en un bucle parecido.

Juan Hernández Armenteros ${ }^{17}$, pone énfasis en que la Universidad no hace otra cosa que reclamar incremento de financiación, siguiendo un modelo clientelista y meramente incrementalista, y que aunque es cierto que en España la financiación pública de la universidad no llega a la media de la OCDE, lo cierto es que no se hace acreedora a esa mejora en la financiación, ya que ni siquiera ha sido capaz de implantar de modo generalizado un sis-

\footnotetext{
${ }^{15}$ Comentarios a la Ley de Universidades. Civitas 2009. Página 1299

${ }^{16}$ Este problema ha sido favorecido por la confusión en la que ha caído el TC al identificar al sujeto de la autonomía universitaria, trasladándolo equivocadamente a la abstracción que es la comunidad universitaria. Apostilla Martinez López Muñiz, que muchas de las mejores universidades del mundo carecen en absoluto de un sistema de gestión y gobernanza parecido al español.

${ }^{17}$ La contabilidad de costes en la universidad pública española como herramienta de cambio en sus estructuras productivas y organizativas. Revista de auditoría pública, número 38 de abril del año 2006.
} 
tema de contabilidad de costes cuando era una exigencia unida a la implantación del sistema de Bolonia en la Universidad Pública española.

\section{LEGALIDAD Y EFICIENCIA DE LA FINANCIACION DE LA UNIVERSIDAD PÚBLICA ESPAÑOLA.}

Se trata en este apartado no de entrar en un análisis completo y global de la financiación de la universidad pública española, sino de analizar si debe considerase legal desde la perspectiva del derecho europeo, y si en caso de ser legal de partida, lo es totalmente, o podría haber alguna parte de la misma, o de los usos que se hace con esa financiación, que no lo fuera. Y finalmente, y ya desde el plano de la calidad, se destacaran algunos elementos que ponen de manifiesto carencias que tiene en sí mismo este sistema.

\section{A) LA LEGALIDAD DE PARTIDA DEL SISTEMA DE FINANCIACION.}

Aunque, como se dijo en el comienzo de este artículo, no existe ni en la constitución ni en la legislación española, un modelo o categoría jurídico administrativa de universidad pública y privada, que justifique un tratamiento tan diferente en cuanto a la financiación, este hecho, más como herencia del siglo XIX, que como el resultado de una política jurídico educativa concreta, es el establecido en nuestra legislación estatal y autonómica, y casi nadie se atreve a discutirlo.

Desde la perspectiva del derecho de la UE la financiación de la universidad pública no puede considerarse ilegal, dado que los servicios educativos que prestan las universidades públicas, al estar subvencionados, y tratarse de una actividad que se rige por el principio de solidaridad, y no capitalización, no tiene naturaleza económica, entrando en la categoría de Servicios No Económicos de Interés General, y por lo tanto no le es de aplicación la normativa que prohíbe las ayudas estatales, en particular en el art. 107 del TFUE.

La Directiva 2006/123/CE del Parlamento Europeo y del Consejo, relativa a los servicios en el mercado interior, y la ley española que la traspuso, la 
Ley 17/2009, sobre el libre acceso a las actividades de servicios y su ejercicio (LAAS), establecen que servicio» es "cualquier actividad económica por cuenta propia, prestada normalmente a cambio de una remuneración, contemplada en el artículo 50 del Tratado" $" 18$.

Ya antes, la Sentencia TSJ UE de 7 de diciembre de 1993, en el caso C109/92, Stephan Max Wirth c/Landeshauptstadt Hannover19, había dicho que sólo la educación financiada públicamente no tiene la consideración de servicio a los efectos del Tratado.

La Comunicación de la Comisión Europea relativa al concepto de ayuda estatal conforme a lo dispuesto en el art. 107.1 del TFUE (2016/C 262/01), apartados 28 al 30, señala que la educación organizada, financiada y supervisada por el Estado, es una actividad no económica, y por lo tanto, las ayudas que se otorgan no se consideran ayudas a los efectos de la artículo 107.1 del TFUE, por lo que quedan al margen de la aplicación de la normativa que pretende evitar las distorsiones a la competencia, lo mismo que sucede con otro tipo de actividades regidas por el principio de solidaridad, y no el de capitalización, como la sanidad y seguridad social. Pero esta Comunicación también aclara, que los servicios educativos financiados predominantemente por los alumnos, por sus padres, o por ingresos comerciales, si tienen naturaleza económica. También aclara que en muchas ocasiones entidades públicas ofrecen servicios educativos, que por su naturaleza y estructura de financiación, deberían ser considerados también como servicios de naturaleza económica.

Mucho más recientemente, la sentencia del TSJ de la UE, de 27 de junio de 2017, en el asunto C74/16, Escuelas Pías con el Ayuntamiento de Getafe por exención del ICIO, ha dejado claro que los servicios educativos pagados por las familias son servicios económicos ya que: los cursos que imparten

\footnotetext{
${ }^{18}$ La propia Directiva en el párrafo $3^{\circ}$ su artículo 1 aclara en los apartado 3. La presente Directiva no trata la abolición de monopolios prestadores de servicios ni las ayudas concedidas por los Estados miembros amparadas por normas comunitarias sobre competencia. La presente Directiva no afecta a la libertad de los Estados miembros de definir, de conformidad con la legislación comunitaria, lo que consideran servicios de interés económico general, cómo deben organizarse y financiarse dichos servicios con arreglo a las normas sobre las ayudas públicas y a qué obligaciones específicas deben supeditarse.
} 
centros de enseñanza financiados esencialmente con fondos privados constituyen servicios, puesto que el objetivo perseguido por tales centros consiste, en efecto, en ofrecer un servicio a cambio de una remuneración. La sentencia hace hincapié en que precisamente sería una contabilidad separada, la que permitiría deslindar que actividades podrían quedar exentas del impuesto por no ser económicas, y las que no, por tratarse de actividades económicas.

La jurisprudencia europea precisa también que concepto de Servicio No Económico de Interés General es el que tiene que ver con el núcleo de la actividad, y así las sentencias Kohll (C-158/1996) y Decker (C$120 / 95)^{19}$, limitan la aplicación del régimen comunitario de los servicios de interés general al ámbito estricto y propio de tales servicios, a sus aspectos nucleares.

\section{B) Posible ABUSO DE POSICION DE DOMINIO.}

La Universidad Pública presta mucho más servicios que los meramente relacionados con la docencia oficial y la investigación: docencia no oficial, no sometida a precios públicos, que da lugar a la obtención de los llamados títulos propios, formación continua, actividades de consultoría o de prestación de servicios en general, a través principalmente de OTRIS, u Oficinas de Transferencia de la Investigación, Fundaciones Universidad-Empresa, etc. Además gestionan editoriales, tiendas, alquilan sus espacios para restaurantes y cafeterías, etc.

Salvo que pudiera demostrarse que la docencia no oficial, que se ofrece a precio libre no tasado, y que los servicios de consultoría, asesoría o investigación, que de igual manera se ofrecen a precio libre, se realizan con recursos humanos y materiales no financiados para la docencia o la investigación oficial, cosa que sólo se podría realizar si tuvieran implantadas estas universidades un sistema de contabilidad analítica, con la que pudieran defender la separación de recursos para otras actividades, se podría entrar en un caso de abuso de posición dominante, regulada en el art. 102 del TFUE, y en el art. 2

${ }^{19}$ Analizadas por Tomás de la Cuadra Salcedo y Fernández del Castillo en la monografía los Servicios Públicos tras las Crisis Económica. Tirant Lo Blanch. Valencia 2017. 
del Ley 15/2007, de 3 de julio, de Defensa de la Competencia, puesto que con recursos financiados para un fin, se compite en el mercado libre con otras finalidades.

La contabilidad de costes apenas está implantada en la universidad española. Así lo expresa Juan Hernández Armenteros, en el artículo citado con anterioridad, así como otro del año 2015 llamado "La financiación universitaria como instrumento dinamizador de cambio en la universidad pública española" ${ }^{20}$, escrito junto a José Antonio Pérez García, en el que insisten en la necesidad de contar con sistemas de contabilidad de costes tanto para objetivar las decisiones del indole interno, como para establecer programas de buenas prácticas entre las diferentes unidades productivas y los servicios prestados por las universidades.

El informe WERT del año 2013, en su página 52, ya decía que los sistemas de contabilidad analítica se encuentran aún sin constituir de forma generalizada en las comunidades autónomas y por tanto también en las universidades, a pesar de ser un requisito para la implantación de los nuevos grados del plan de Bolonia. ${ }^{21}$

El catedrático Iñigo Saz Rubiales en la ponencia denominada "La universidad: entre el servicio público y la competencia" 2 , recoge los casos en los que dos organizaciones denunciaron a sendas universidades politécnicas españolas por competencia desleal. En el primero de los casos, la Asociación Catalana de Escuelas Náuticas (ACEN) denunció a la Universidad Politécnica de Cataluña por organizar unos cursos de navegación de recreo, impartidos por la Facultad de Náutica. En el segundo de los casos, la Universidad Politécnica de Valencia fue denunciada por el Colegio de Ingenieros de Caminos, Canales y Puertos de la Comunidad Valenciana por competencia

${ }^{20}$ CIAN-Revista de Historia de las Universidades, 18/1 (2015), 79-96 ISSN: 1988-8503 / www.uc3m.es/cian

${ }^{21}$ Antes, en el 2011, se había aprobado por el Consejo de Universidades y la Conferencia General de Política Universitaria, el modelo de contabilidad analítica. Sin embargo, un informe de la CRUE de 2016, en relación a una encuesta realizada a 38 universidades, que eso si, habían constituido comisiones de trabajo a estos efectos, indicaba que solo 10 universidades informan sobre el coste de las titulaciones, para cuyo cálculo solo se aplicaba el modelo de contabilidad analítica en 3 universidades.

${ }^{22}$ XII Congreso de la AEPDA Salamanca. Febrero 2018. 
desleal en la realización con terceros de contratos, proyectos y direcciones de obras. En ambos casos el resultado final en los tribunales fue contrario a los intereses de los denunciantes, pero es importante destacar como la sentencia que puso fin al segundo de los casos, la STS de 27 de octubre de 2005, deja abierta a la posibilidad a que en otros casos similares, la actividad realizada por la universidad en el ámbito de este tipo de contratos, o de títulos propios, por más que esté amparada en la legislación universitaria, puede ser potencialmente contraria a la normativa protectora de la competencia. ${ }^{23}$

Analizada la cuestión desde otra perspectiva, podemos decir que si en el sueldo del PDI de la Universidad Pública, se compensa tanto su actividad docente como investigadora, ¿no debería permanecer en la Universidad - o incluso ir a la CA que la financia -, la totalidad, o al menos una parte muy importante, de lo que se facturara a terceros por servicios vía OTRI, etc., que con eso se compensaría de los pagos que realiza a su personal, y limitaría el esfuerzo de su financiador que en definitiva somos todos?, de otro modo podría darse un caso de enriquecimiento injusto. Cuestión distinta es la existencia de una compensación variable por resultados a favor del PDI que participe en esos trabajos a terceros, pero una cosa es esta, y otra muy distinta es que la gran mayoría de lo pagado por terceros se lo quede el propio PDI, al que ya se le paga por enseñanza e investigación, por lo que de alguna manera, y por el mismo trabajo, pudiera estar recibiendo una compensación doble. El juego sería parecido al de las costas judiciales. El cliente que contrata a un abogado tiene derecho a resarcirse de los gastos incurridos por su parte en caso de que la condena en costas les favoreciera.

También podría considerarse un abuso de posición de dominio, la práctica de la mayoría de universidades públicas, eso sí condicionada por las Ordenes de

23 "En definitiva, no basta la invocación de la habilitación otorgada por el art. 11 LRU (actual $83 \mathrm{LOU}$ ), que permite realizar trabajos técnicos o impartir docencia no universitaria o por el art. 28 LRU (actual 34.1 LOU) que habilita igualmente a impartir enseñanzas no universitarias para entender que la actuación de estas ha sido correcta desde todas las perspectivas; estos preceptos legitiman dicha actuación respecto de las normas reguladoras de las universidades y de la función pública, e indirectamente, respecto a algún aspecto de la normativa de la competencia, pero no respecto de todas las potenciales infracciones de la Ley de defensa de la competencia”, como señala la propia STS de 27 de octubre de 2005 (FD 5o). 
Tasas y Precios públicos aprobadas por las respectivas CCAA, de aplicar a los alumnos de fuera de la UE precios inferiores al coste real de los estudios.

\section{C) DEFECTOS DEL SISTEMA DE FINANCIACION.}

Ya hemos visto que considerada en términos generales, desde la perspectiva del derecho europeo, la financiación de la universidad pública española no puede considerarse ilegal, aunque podrían darse casos de abuso de posición de dominio. Corresponde ahora ver que se puede decir del sistema mismo desde el punto de vista de la equidad, la eficiencia y la competitividad.

\section{1.- Falta de equidad.}

\subsection{Precios públicos altamente subvencionados de partida.}

Un sistema universitario público como el español que financia de entrada a todos los alumnos por igual, sea cual sea su nivel de rentas, entorno a un $75 \%$ de los costes reales de cada plaza universitaria, adolece ya de partida de un problema de equidad, ya que el papel de las becas según niveles de renta, sólo entra a jugar sobre el precio público que efectivamente paga el alumno. Embid y Michavila ya denunciaron este asunto en el 2001, ya que esta política de precios tan bajos- hoy es verdad que son algo más altos - podría suponer un efecto distinto al querido, ya que podría haber transferencias de rentas a la inversa, de familias de menos recursos a otras que tienen más. ${ }^{24}$

En parecidos se expresaba el que fuera Secretario General de Universidades, Emilio Lamo de Espinosa ${ }^{25}$, quien entendía que es injusto que la sociedad sufrague con impuestos un servicio que redunda en beneficios de unos pocos, y no

\footnotetext{
${ }^{24}$ Para Embid y Michavila, el problema arranca de un axioma sobreentendido acerca de que un nivel bajo de precios, facilita el acceso a la educación superior de las clases sociales desfavorecidas, lo que favorecería el valor constitucional de la igualdad en relación al derecho de educación. Hacia una nueva Universidad. Apuntes para un debate. Tecnos 2001

${ }^{25}$ Cita recogida en la página 19 de la monografía de Javier Fernández Fernández, Financiación de la Universidad Pública en Tiempos de Crisis. Los Consejos Sociales. McGraw Hill Education. INAP.2018. ISBN 978-84-486-1524-6.
} 
siempre los más pobres; en cierta medida la Universidad es un mecanismo de transferencias de rentas, pero inverso, de pobre a ricos y no al revés.

\subsection{Los beneficios de los títulos universitarios.}

A lo anterior abunda el hecho de que aunque la enseñanza universitaria tiene efectos favorables para la sociedad en general, lo cierto es que a quien primero beneficia la obtención de un grado universitario es al propio graduado, ya que con la obtención de un título universitario, tiene muchas más posibilidades de obtener trabajo, y que además este sea mucho mejor remunerado. En el último informe la Universidad Española en cifras 2016/2017 $7^{26}$, se indica que estando la tasa media de desempleo en un $16,7 \%$, la misma baja al 9,3\% cuando se tienen estudios superiores, y sólo al 4,2\% cuando los estudios son de doctorado. En ese informe también se indica que los niveles de renta de los universitarios son un $50,9 \%$ superiores a los niveles de los que no lo son.

A este hecho abunda el que la universitaria, aunque muy importante, es un tipo de enseñanza no obligatoria, y de que en España el gasto medio de las familias en educación en bastante bajo, ya que se dedica sólo $414 €$ de los $29.188 €$ que gastan de media al año, y se sitúa por debajo de lo que emplean para alcohol y tabaco ${ }^{27}$. Además muchas familias que financian la universidad no hacen uso de sus servicios. ${ }^{28}$

\subsection{Inequidad territorial.}

Para Hernández Armenteros la inequidad de los costes de la enseñanzas universitarias tiene un doble origen: por un lado tiene un carácter territorial ya que para un servicio prácticamente igual se pueden llegar a pagar cantidades muy distintas, siendo los extremos opuestos Galicia en cuanto menores precios, y Cataluña

\footnotetext{
${ }^{26}$ Elaborado por Juan Hernández Armenteros y José Antonio Pérez García para la CRUE.

${ }^{27} \mathrm{https}$ ://www.libremercado.com/2018-06-29/asi-gastan-su-dinero-las-familias-espanolas29200-euros-por-hogar-en-2017-1276620896/

${ }^{28}$ En esta misma línea se pronunciaban Gonzalo Sanz-Magallón Rezusta, pedro Schwartz Girón, y María Encina Morales de Vega en el año 2009, quienes entendían que los beneficios individuales que comportan los estudios universitarios, más el limitado coste medio que emplean las familias en educación - en ese momento era de $103 €$ al año -, hacían necesario un cambio en la política de precios.
} 
en cuanto a los mayores, que pueden variar en cuanto al precio del crédito en el triple. Inequidad que al parecer el ministro Pedro Duque se proponía corregir ${ }^{29}$. El segundo motivo de esta inequidad ya nos es conocido, y tiene que ver con el pago de precios con independencia del nivel de renta de las familias. ${ }^{30} \mathrm{El}$ informe sobre la Financiación del Sistema Universitario Español de 20 de abril de $2007^{31}$, realizado por la Comisión de Financiación creada por el Consejo de Coordinación Universitaria, se pronunciaba en esta misma línea destacando la necesidad de evitar "la actual estructura de precios públicos regresiva, que transfiere renta de quienes tienen menos recursos a quienes tienen más, y la inequidad añadida que supone su aplicación a un servicio que, como la educación universitaria, presenta un elevado grado de apropiación directas de los beneficios derivados de su provisión."

Finalmente un informe de la CNMC, de 14 de julio de $2016^{32}$, del que hablaremos con detalle, incide, en otros muchos aspectos relativos a nuestros sistema universitario y la competencia, en que el sistema de tasas es ineficiente dado el elevado retorno privado que tienen la educación universitaria con respecto al retorno social.

\section{2.- Falta de eficiencia.}

Como se ha comentado, en el año $2006^{33}$ Hernández Armenteros ya denunciaba la falta de calidad técnica del sistema de financiación universitaria, donde se carece de una estructura de costes reales, y de un sistema de infor-

\footnotetext{
${ }^{29} \mathrm{https} / /$ cincodias.elpais.com/cincodias/2018/10/31/fortunas/1540984739_631115.html

${ }^{30}$ Las cifras recogidas en el cuadro 2 referidas a la evolución de los ingresos liquidados por precios y tasas de las universidades públicas de las CCAA. muestran acusadas diferencias. Negativas para Galicia, -3,98, y elevadas para Cataluña, con aumentos del 142,64\%. La inequidad se agranda al considerar que los precios universitarios se pagan con independencia del nivel de renta de la familia del alumno. Las fuentes de financiación de las universidades públicas españolas. Nueva Revista de Política, Cultura y Arte. № 163. La universidad 2018. UNIR

${ }^{31}$ Publicado por Juan Hernández Armenteros, miembro de la Comisión en representación de la CRUE, en la Revista de estudios regionales número 79 año 2007, página 241-287.

${ }^{32} \mathrm{https} / /$ www.cnmc.es/file/107312/download

${ }^{33}$ La contabilidad de costes en la universidad pública española como herramienta de cambio en sus estructuras productivas y organizativas. Revista de auditoría pública, número 38 de abril del año 2006
} 
mación mucho más completo que el mero registro contable de gastos. Todo ello agudizado por el gran crecimiento de la universidad en los últimos años, y la descentralización de la misma. ${ }^{34}$ Hernández Armenteros pedía a las universidades que no confundieran autonomía financiera con opacidad en la gestión, y que esa circunstancia hacía precisamente el que perdiera fuerza las reiteradas peticiones de la universidad dirigidas a un incremento de su financiación. ${ }^{35} \mathrm{La}$ descentralización había generado muy distintos modelos de financiación, la mayoría ajenos a cualquier elemento objetivo. Modelos no consolidados que exigían que cada año se debiera iniciar un proceso de negociación inspirado por el modelo incrementalista. Escasamente existían esquemas financieros de carácter normativo, o fórmulas de tipo contractual como los contrato programas.

Nueve años después, el propio Hernández Armenteros escribió junto José Antonio Pérez García, "la financiación universitaria como instrumento dinamizador de cambio en la universidad pública española”, donde empezaban por dejar bien claro que la financiación universitaria seguía siendo un tema pendiente de resolución. Los autores acusaban a las leyes orgánicas universitarias y a su desarrollo reglamentario de haber tratado el asunto de la financiación de manera demasiado genérica. ${ }^{36}$

\section{3.- Financiacion no favorecedora de la competencia.}

La última perspectiva de del sistema de financiación de la universidad española, tiene que ver con el análisis de en qué medida el sistema propicia la competencia, o si por el contrario, no la favorece, no pensando únicamente

\footnotetext{
${ }^{34}$ La solución que proponía entonces era la implantación de un sistema de contabilidad analítica que sería el responsable de registrar, calcular y valorar los consumos de recursos que la universidad ha empleado en la ejecución de sus actividades.

35 "Confundir ausencia de lucro con opacidad operativa es un grave error que daña la credibilidad social de las instituciones universitarias y que, a su vez, debilitan los argumentos que justifican la necesidad de mejorar la financiación universitaria. Ídem página 97.

${ }^{36}$ En cuanto a la tensión existente entre universidades y CCAA indican: "El órgano financiador no puede ser cautivo de las actuaciones que cada universidad haya decidido emprender, ni las instituciones pueden estar pendientes de la discrecionalidad, cuando no arbitrariedad, de los agentes financiadores.
} 
en la competencia entre la universidad pública y la privada, sino también entre las universidades públicas entre sí.

La CMNC emitió un importante informe el 14 julio de $2016^{37}$, en el marco del recurso contencioso-administrativo interpuesto por ella misma contra varios de los requisitos establecidos en el Acuerdo de 27 de octubre de 2015 del Gobierno de Aragón ${ }^{38}$, por el que se establecen los objetivos, criterios y requisitos que guiarán la programación de las enseñanzas universitarias oficiales en la Comunidad de Aragón para el periodo 2016-19 (en adelante Acuerdo del Gobierno de Aragón de 27-10-15). Dicho recurso se interpuso al amparo de las facultades que le otorga el artículo 27 de la Ley 20/2013, de 9 de diciembre, de Garantía de la Unidad de Mercado - LEGUM-, y ello por considerar los requisitos de este Acuerdo contrarios a los principios de proporcionalidad, libre iniciativa económica, y no discriminación de los artículos 5, 16 y 18 de dicha Ley. Recurso contencioso administrativo que no ha tenido resolución hasta la fecha, y al que siguió otro de Constitucionalidad ${ }^{39}$ que interpuso el Gobierno del presidente Rajoy frente a la modificación el artículo 5 de la Ley 5/2005, de 14 de junio, de Ordenación del Sistema Universitario de Aragón -LOSUA-, que básicamente consistía en prohibir la implantación de titulaciones universitarias previamente establecidas en los campus de la Universidad de Zaragoza de Huesca, Teruel, y el centro adscrito de La Almunia de Doña Godina, asunto sobre la que abundaremos más adelante.

El informe, por lo que nos interesa en este momento, entiende que las actividades de las universidades privadas entran en el ámbito de la LEGUM ${ }^{40}$, y parte -citando a Aghion et alia (2010)-, de la evidencia empírica, ya no sólo intuitiva, de los beneficios de la competencia para la calidad de las uni-

\footnotetext{
${ }^{37} \mathrm{https} / / /$ www.cnmc.es/file/107312/download

${ }^{38}$ Esos acuerdo de habían publicado en el Boletín Oficial de Aragón el 25 de noviembre de 2015, por medio de la ORDEN de 30 de octubre de 2015, de la Consejera de Innovación, Investigación y Universidad, por la que se publica el Acuerdo de 27 de octubre de 2015, del Gobierno de Aragón.

${ }^{39} \mathrm{https}: / /$ www.boe.es/boe/dias/2016/11/21/pdfs/BOE-A-2016-10921.pdf

${ }^{40}$ En el mismo sentido se había pronunciado el 25 de junio de 2014, la Secretaria del Consejo para la Unidad de Mercado - SECUM- , tras denuncia realizada por la Universidad San Jorge a una normativa anterior y semejante del Gobierno de Aragón.
} 
versidades $^{41}$, para resaltar una serie de fallos del sistema universitario español desde la perspectiva de la competencia.

El informe en páginas 15 a 18 analiza los principales obstáculos a la competencia:

1. Sistema que se basa en criterios de cantidad en lugar de calidad. ${ }^{42}$

2. Las universidades carezcan de libertad y autonomía para determinar las tasas académicas, que ni siquiera llegan al 25\% de los costes totales, siendo el resto de la financiación vía transferencias corrientes y de capital. ${ }^{43}$

3. Sistema muy rígido de contratación del personal docente e investigador. ${ }^{44}$

4. Alto control administrativo de la oferta de títulos universitarios oficiales, que limita la autonomía de las universidades para organizar su oferta, diferenciarse y competir.

5. Restricciones específicas a las universidades privadas. Los controles administrativos tienen todavía menos sentido con respecto a estas, en aplicación de todos los criterios y princi-

\footnotetext{
${ }^{41}$ Aghion et alia (2010) analizan el efecto de la autonomía y la competencia entre universidades en su calidad investigadora. Tanto para Estados Unidos como para Europa, proporcionan evidencia empírica que confirma la relación positiva entre autonomía y competencia y producción investigadora.

${ }^{42}$ Se trata de una forma de financiación que no incentiva la mejora, y contribuye a generar un panorama relativamente homogéneo en términos de calidad, que en parte explica la escasa movilidad estudiantil.

${ }^{43}$ El informe cita otro de la OCDE de 2005: el nivel actual de tasas tan bajo distorsiona las decisiones de inversión en capital humano, contribuye a que exista demasiada demanda de educación universitaria, y refuerza el desajuste entre demanda y oferta de habilidades y formación en el mercado laboral.

${ }^{44}$ En el que las remuneraciones son también fijas y parecidas, con la consecuencia de que la movilidad entre universidades sea escasa, y de hecho no exista un mercado de profesores a nivel nacional, además de impedir, o al menos restringir la capacidad de captar talento en el mercado internacional.
} 
pios, que trajo consigo la Directiva de Servicios, su ley de trasposición, y la LEGUM.

6. Finalmente el informe entiende que el sexto obstáculo, que afecta de modo particular a los alumnos y profesorado, lo constituye la falta de transferencia de información sobre distintas variables. ${ }^{45}$

En conclusión: aunque el sistema de ayudas de los poderes públicos a las universidades de titularidad pública en España, no sea contrario al derecho europeo que prohíbe las ayudas públicas a los operadores económicos, sí que puede originar situaciones de abuso de posición dominante por parte de las universidades, sobre todo en materia de enseñanza no oficial y servicios a terceros, y en cualquier caso, adolece de graves fallos en materia de equidad, eficiencia y favorecimiento de la competencia.

Como dice Martínez López Muñiz: antes o después habrá que cuestionarse la justificación de la radical diferencia de financiación entre públicas y las privadas $^{46}$.

\section{REGIMEN JURIDICO DE LA PRESTACION DE SERVICIOS ECONOMICOS EN TERRITORIO DE LA UNION EUROPEA.}

Para poder enmarcar adecuadamente este elemento, debemos partir de fijar la naturaleza de los servicios que prestan las universidades privadas, y para ello nos remitimos en bloque a lo ya dicho sobre la legalidad del sistema de ayudas a las universidades públicas, y es que es precisamente toda esta normativa y jurisprudencia interpretada a sensu contrario, la que nos dice que los servicios educativos pagados por los usuarios o sus familias, sí que tienen la naturaleza de servicio económico.

\footnotetext{
${ }^{45}$ Opacidad relacionada con elementos esenciales para una mejor elección: calidad docente, conocimientos y habilidades que se pueden adquirir, empleabilidad, vacantes de profesorado, etc.

${ }^{46}$ Comentarios a la Ley Orgánica de Universidades. Civitas. 2009. Las Universidades privadas.
} 
Pues bien, la calificación de servicio de naturaleza económica tiene, o mejor dicho, debería de tener, la importante consecuencia de la aplicación de todo el bloque normativo que flexibiliza la prestación de este tipo de servicios, contenido principalmente en la ya citada Directiva de Servicios en el mercado interior, traspuesta a España por la LAAS 17/2009 y la LEGUM 20/2013.

Pero como veremos con detalle, los principios jurídicos que contiene este bloque normativo parecen no haber sido recibidos por el derecho educativo español, incluidos el universitario. Este análisis lo vamos a dividir en el estudio de los principios aplicables, y las prohibiciones dirigidas a la administración.

\section{A) PRINCIPIOS}

1. Principio de simplificación de cargas administrativas.

2. Principio de libertad de establecimiento y no discriminación.

3. Principio de subsidiariedad del sistema de autorización.

4. Principio de necesariedad y proporcionalidad en la limitación de las condiciones para la concesión de autorización.

5. Principio de información y ventanilla única.

\section{1.- Principio de simplificación de cargas administrativas}

Recogido en el art. 5 de la Directiva, el 17 de la LAAS y el 7 de la LEGUM, que a su vez puede desdoblarse en las siguientes partes:

a) Verificación de los procesos internos.

b) Reforma interna para la verificación de procesos.

c) Confianza en la documentación administrativa de otros países miembros.

d) No exigencia de originales, copias compulsadas ni traducciones juradas. 
e) No generación de un exceso de regulación o de duplicidades.

Algunos de estos principios, como el c y el d, podrían ser de los exigibles directamente a la administración, y en cambio los otros tres a, b y e, tendrían las consideración de los llamados principios de "better regulation", que van dirigidos más bien a la administración para que sea ella la que vaya reformando sus procedimientos o normas internas.

\section{2.- Principio de libertad de establecimiento y no discriminación.}

Se trata de uno de los principios capitales de la UE, una de las llamadas libertades comunitarias, recogida actualmente en el art. 49 del TFUE. Los efectos de este principio no deben considerarse únicamente en lo relativo a un operador comunitario que quiere establecerse en España, sino también en el ámbito interno, en lo que tiene que ver con un operador nacional que quiere establecerse en otra parte del territorio. Así lo contemplan el art. 17 de la LAAS y el art. 3 de la LEGUM. ${ }^{47}$

No tendría sentido que la libertad de establecimiento, o el derecho europeo en general, concediera una serie de derechos en España a centros universitarios de otros estados miembros, y no se los diera a los propios centros universitarios españoles. Se trataría de la aplicación interna del derecho europeo del que trata José María Rodríguez de Santiago en su artículo: ¿existe libertad de creación y establecimiento de Universidades en España? ${ }^{48}$ En cualquier caso, estos principios ya están contenidos en leyes nacionales como la LAAS, y la LEGUM.

\footnotetext{
${ }^{47}$ Recordemos sobre este particular que la reciente declarada constitucional por la de Sentencia del Tribunal Constitucional de 22 de julio de 2017, declaro constitucional la LEGUM, con la única excepción de negar la eficacia extraterritorial de las decisiones de unas CCAA con respecto a otras, salvo que exista un estándar normativo nacional previo. Es obvio que en materia de Universidades, la LOU, y la amplia normativa estatal de desarrollo constituyen un verdadero estándar nacional.

${ }^{48}$ Revista española de Derecho Administrativo 193. Julio- Septiembre 2018. ISSN 02108461
} 


\section{3.- Principio de subsidariedad del sistema de autorización}

Este es uno de los principios más importantes de este bloque normativo, conforme al cual, el sistema autorización, tan generalizado en nuestro derecho administrativo, y en particular tan desarrollado en el ámbito del derecho educativo, debería pasar a tener un carácter subsidiario cuando se trate de la autorización de servicios educativos no subvencionados, dado - insistimossu carácter de servicio económico. Veremos como la realidad de la normativa española no atiende en absoluto a este principio, y las administraciones españolas, especialmente las autonómicas, no se resisten a perder el control sobre toda actividad educativa, ya sea esta pública y subvencionada, o ya lo sea privada y pagada por las familias. Es más, los controles administrativos en lugar de ir a menos, van a más, e incluso nacen de normas que no son propiamente jurídicas, sino de instrucciones internas de ciertos organismos, lo que la doctrina ha calificado como "soft law" o derecho blando.

Sin entrar en mayor profundidades jurídicas, sino únicamente guiándonos por el sentido común, ya podríamos llegar a la lógica conclusión de que no tiene sentido que se someta a los mismos controles autorizatorios al sistema universitario público, que es financiado con los recursos de todos, que al de titularidad privada, que no lo es. Esta normativa europea responde a esta lógica, que además promueve la competencia y con ello la mejora general del sistema universitario. Según esta normas la autorización como instrumento normativo debería pasar a tener un carácter meramente subsidiario, frente a otros instrumentos como la declaración responsable o la comunicación a posteriori, que si deberían tener un carácter más principal.

En concreto el art.9 de la Directiva y 5 de LAAS $17 / 2009^{49}$, establece que los Estados miembros solo podrán supeditar el acceso a una actividad de

${ }^{49}$ a) No discriminación: que el régimen de autorización no resulte discriminatorio ni directa ni indirectamente en función de la nacionalidad.

b) Necesidad; la de autorización esté justificado por una razón imperiosa de interés general,

c) Proporcionalidad: que dicho régimen sea el instrumento más adecuado para garantizar la consecución del objetivo que se persigue porque no existen otras medidas menos restrictivas que permitan obtener el mismo resultado, en particular cuando un control a posteriori se produjese demasiado tarde para ser realmente eficaz. Así, en ningún caso, el acceso a una actividad de servicios o su ejercicio se sujetarán a un régimen de autorización cuando sea 
servicio y su ejercicio a un régimen de autorización cuando se reúnan las siguientes condiciones:

a) No discriminación.

b) Que la necesidad del régimen de autorización está justificada por una razón imperiosa de interés general.

c) Proporcionalidad, el objetivo perseguido no se pueda conseguir mediante una medida menos restrictiva.

El art. 3.1 de la LEGUM establece los criterios para considerar imperioso el interés general, que son a su vez derivados de la jurisprudencia del Tribunal de Justicia de las Comunidades Europeas, limitándose a los siguientes:

- el orden público, la seguridad pública, la protección civil, la salud pública,

- la preservación del equilibrio financiero del régimen de seguridad social,

- la protección de los derechos, la seguridad y la salud de los consumidores, de los destinatarios de servicios y de los trabajadores, las exigencias de la buena fe en las transacciones comerciales,

- la lucha contra el fraude, la protección del medio ambiente y del entorno urbano, la sanidad animal, la propiedad intelectual e industrial

- la conservación del patrimonio histórico y artístico nacional y los objetivos de la política social y cultural.

Una vez expuesto el régimen de autorización, nos tendríamos que preguntar, si en todos los casos debería esperarse a que la administración modificara sus

suficiente una comunicación o una declaración responsable del prestador mediante la que se manifieste, en su caso, el cumplimiento de los requisitos exigidos y se facilite la información necesaria a la autoridad competente para el control de la actividad. 
normas, para ir eliminando autorizaciones, sustituyéndolas por los sistemas alternativas antes mencionados, o el administrado tendría derecho legítimo de, ante una posible inactividad de la administración, considerar aplicable directamente la normativa citada, por encima de la concreta norma administrativa, que además, como más adelante veremos, casi siempre va a ser de rango inferior, cuando no producto directamente del soft law, y desarrollar un aspecto concreto de sus servicios educativos, aun a pesar de no tener la autorización administrativa expresa que teóricamente correspondería. ¿Podrían los tribunales amparar la actuación de un administrado en un caso como el expuesto? Es cierto que si contestamos que si se podría generar una cierta inseguridad jurídica, pero también es cierto que si contestamos que no, se dejaría en manos de la administración el desarrollo de unos principios jurídicos de rango superior, que además siempre le van a molestar porque supondría la pérdida de control en un campo tan sensible como el de la educación universitaria.

Todo además puede depender del caso concreto, pues no es lo mismo empezar a actuar como universidad sin tener una autorización previa en forma de ley de reconocimiento, que simplemente incrementar un porcentaje de los alumnos de nueva entrada de grado con una declaración responsable de tener los recursos humanos y materiales con los que atender a este incremento de alumnos, o incluso poner en marcha una determinada titulación universitaria, previamente verificada, pero que no cuenta con la autorización de puesta en funcionamiento de la CA correspondiente, porque esta se la niega por ejemplo basándose en la imposición de algunos de los requisitos llamados prohibidos que veremos a continuación.

\section{4.- Principio de necesariedad y proporcionalidad en las condiciones para la concesión de autorización.}

Pues bien, con independencia de que el sistema de autorización debería ser excepcional en lugar de habitual, lo cierto es que según el Art. 10 de la Directiva y 9 de la LAAS, la autorización deberá ser ajustada al caso concreto, evitando un ejercicio arbitrario de esta facultad autorizatoria, y además de ser no discriminatorio, debe ser claro e inequívoco, objetivo, hecho público con antelación, transparente y accesible, y proporcionado. 
Necesariedad y proporcionalidad son los dos requisitos a los que habitualmente se refiere la jurisprudencia, en particular la europea, al analizar las autorizaciones. El juicio de necesariedad en realidad tiene que ver con el sentido mismo de la existencia de la autorización, sin embargo el de proporcionalidad sería posterior, partiríamos ya del punto en el que la necesidad ya ha sido acreditada, "teóricamente", y el análisis debería centrarse en si los requisitos autorizatorios son ajustados al caso concreto, o son exagerados, análisis que en caso de discrepancia sólo podrán realizar los tribunales.

\section{5.- Principio de información y ventanilla única}

Estos principios regulados en los arts. 6 y 7 de la Directiva de Servicios, y 18 y 19 de la LAAS 17/09, tendrían un carácter auxiliar o instrumental con respecto a los anteriores, aunque qué duda cabe que ya que se debe estar sometido a un enjambre de autorizaciones que depende de diferentes administraciones u organismos, la ventanilla única simplificaría las cosas enormemente. En cualquier caso, sí que parece evidente que estos principios forman parte del llamado "better regulation," ya que si España carece de ventanilla única en este campo, poco más podrán hacer los administrados que poner la correspondiente denuncia a la Comisión Europea.

\section{B) CRITERIOS DE AUTORIZACION PROHIBIDOS.}

Recapitulando, en el apartado anterior hemos visto una serie de principios que deben regir el sistema de prestación de los servicios de las universidades privadas, y en general cualquier tipo de enseñanza que no sea subvencionada por los poderes públicos.

La aplicación de alguno de estos principios, como por ejemplo la disminución paulatina de trámites y duplicidades administrativas, y la creación de una ventanilla única, pertenecerían al ámbito del llamado "better regulation," por lo que no cabría en principio realizar una exigencia directa a la administración, sino en todo caso una denuncia a la comisión por incumplimiento del derecho europeo. Otro bloque de estos principios incluyen: 
- Los criterios que deben de tomarse en cuanta para discernir cuando la prestación de un servicio debe ser sometida a un sistema de autorización, y cuando podría sustituirse por otro menos gravoso como pueda ser la declaración responsable o la comunicación a posteriori, en el bien entendido de que estos dos segundos sistemas deberían ser principales, y el de autorización debería pasar a ser subsidiario.

- Los criterios que modulan la autorización en caso de ser esta necesaria, y que pasan por la superación de un test de proporcionalidad.

Lo que sucede, es que si los poderes públicos - tal y como se puede prever - se niegan a cambiar la normativa actual, para sustituirla por otra en la que el principio de autorización pasase a tener un carácter subsidiario, y se empeña en insistir en la autorización como instrumento general, la cuestión de la necesariedad y la proporcionalidad puede ser objeto de arduas discusiones, que llegado el caso sólo podrán resolver los tribunales.

Finalmente nos encontramos otro bloque normativo en esta materia, mucho más claro, en lo que ya no cabe hablar de "better regulation", ni de principios a desarrollar, ya que son de aplicación directa, y en ellos hay a priori mucho menor margen de interpretación, porque se regula con claridad que criterios nunca puede utilizar la administración como requisitos en los que basar una autorización; son los llamados requisitos prohibidos.

Entre los criterios prohibidos que regulan los arts. 14 de la Directiva y 10 de la LAAS $17 / 09^{50}$, destacan los que tiene que ver con la necesidad de acre-

\footnotetext{
${ }^{50}$ Los Estados miembros no supeditarán el acceso a una actividad de servicios o su ejercicio en sus respectivos territorios al cumplimiento de los siguientes requisitos: -requisitos discriminatorios basados directa o indirectamente en la nacionalidad. -prohibición de estar establecido en varios Estados miembros.

-limitaciones de la libertad del prestador para elegir entre un establecimiento principal o secundario.

-condiciones de reciprocidad con el Estado miembro en el que el prestador tenga ya su establecimiento, con excepción de las previstas en los instrumentos comunitarios en materia de energía.

-aplicación, caso por caso, de una prueba económica consistente en supeditar la concesión de la autorización a que se demuestre la existencia de una necesidad económica o de una demanda en el mercado, a que se evalúen los efectos económicos, posibles o reales, de la
} 
ditar una demanda, una respuesta del mercado, efectos económicos, o la adecuación a los objetivos de una programación. Estos son requisitos que es lógico que pudiera exigir un financiador a una entidad financiada, por lo tanto es lógico que se lo exijan las CCAA a sus universidades públicas, pero no existe la misma razón para que se exija también a las privadas, que ya tienen sus propias entidades titulares, y sus consejos de administración, comités directivos o patronatos, a los que someter a autorización su desarrollo, además de rendir cuentas. Pero vamos a comprobar como esta lógica se quiebra, y los gobiernos regionales no distinguen entre universidades públicas y privadas a la hora de exigir esta información.

Además este tipo de pruebas económicas, admiten múltiples elaboraciones, en este campo vale la expresión tan comúnmente usada de que el "papel lo aguanta todo"; puede haber un potencial mercado al que un operador económico no sepa satisfacer, y al contrario, puede no existir un mercado a priori, que luego una nueva oferta se sabe ganar. Con este tipo de normas, la administración siempre va a tener la fácil solución de entender no acreditada la existencia de un mercado suficiente, para así resolver negativamente la solicitud, por ejemplo, de puesta en marcha, de un nuevo título, y de ese modo proteger a sus universidades limitando la competencia. Sería impensable el que un Ayuntamiento exigiera para autorizar la puesta en marcha de un centro deportivo en su ciudad, que va a competir con sus centros municipales, la acreditación de una respuesta del mercado, en lugar de limitarse a exigirle el cumplimiento de la legislación específica en la materia; es evidente que este tipo de pruebas debería pertenecer únicamente a la esfera del empresario que se juega su dinero. Por la misma lógica, no tiene ningún sentido que una CA niegue a una Universidad privada la puesta en marcha de una carrera determinada, por estar teóricamente toda la demanda absorbida por las universidades ya

actividad o a que se haga una apreciación de si la actividad se ajusta a los objetivos de programación económica fijados por la autoridad competente.

-intervención directa o indirecta de competidores, incluso dentro de órganos consultivos, en la concesión de autorizaciones o en la adopción de otras decisiones de las autoridades competentes, con excepción de los colegios profesionales y de las asociaciones y organismos que actúen como autoridad competente. 
existentes, eso sería tanto como negar la posibilidad de que esa universidad presentará una oferta con mayor calidad en profesorado, recursos, servicios, o precio, al objeto de ganarse el interés de los potenciales alumnos, y con ello generar procesos de competencia, que propicie más calidad en beneficio de todos. Esta es la lógica a la que obedece el establecimiento de los requisitos prohibidos por la UE, pero no es, como vamos a ver, por la que se guían nuestros poderes públicos.

\section{LA REALIDAD: MARAÑA DE AUTORIZACIONES}

Como venimos anticipando, muy al contrario de lo que se debería derivar del régimen jurídico que tendría que regular la prestación de servicios educativos por las universidades de titularidad privada, en la realidad nos encontramos con una enorme maraña de autorizaciones que afectan a todos los aspectos de la vida universitaria. Haremos un pequeño recorrido por ellas.

\section{A) NACIMIENTO DE LA UNIVERSIDAD.}

En el nacimiento de las universidades vía ley de reconocimiento, nos encontramos con otro aspecto limitativo de los derechos, en este caso de los promotores de la Universidad, ya que al requerirse de una norma con rango legal, y nos bastar con una de carácter reglamentario, la decisión final de reconocer o no una universidad privada es incoercible jurídicamente, ya que no puede reaccionar jurídicamente frente a una actuación pasiva de un parlamento regional. No tiene sentido jurídico que los requisitos para el reconocimiento de una universidad privada esté establecidos por una norma de carácter reglamentario, como es en este caso el Real Decreto 420/2015, de 29 de mayo, de creación, reconocimiento, autorización y acreditación de universidades y centros universitarios, y que el reconocimiento sea por ley (art. 4 de la LOU). Este criterio es sostenido tanto por José Luis Martínez López Muñiz ${ }^{51}$, como por José María Rodrí-

\footnotetext{
${ }^{51}$ José Luis Martínez, crítica como muy defectuosa la técnica jurídica que se ha impuesto
} 
guez de Santiago, quien apostilla utilizando para ello doctrina constitucional, que el ejercicio de un derecho fundamental no puede quedar condicionado por una ley singular ${ }^{52}$.

\section{B) CONTROL DE LAS NORMAS DE ORGANIZACIÓN Y FUNCIONAMIENTO.}

La fórmula de control de legalidad que utiliza la LOU para las NOF de la Universidades privadas, en este caso igual que para los estatutos de las públicas, es quizás la más acorde a la naturaleza de las Universidades privadas, ya que estas Normas son elaboradas y aprobadas por la propia Universidad, limitándose la administración regional a hacer un control de legalidad de las mismas, por lo tanto necesariamente a posteriori, una vez que las NOF han sido ya aprobadas. Art.6.2 y 5 de la LOU.

\section{C) AUTORIZACIÓN AUTONOMICA DEL INICIO DE ACTIVIDADES.}

La autorización de inicio de actividades es según el art. 4.4 de las LOU, y el art. 12 del RD 420/2015, competencia de los Gobiernos Regionales. Para Rodríguez de Santiago, esta autorización tendría un carácter claramente reiterativo, ya que las leyes "singulares" de reconocimiento de las universidades privadas, pertenecen al tipo de las llamadas autoaplicativas, cuyo contenido consiste en una actividad típicamente ejecutiva, de aplicación de la norma al caso concreto ${ }^{53}$.

desde la LRU, y que consiste en mantener el criterio de que la creación y reconocimiento de las nuevas universidades, había hacerse por ley, mientras que el gobierno tiene la potestad de determinar con carácter general los requisitos básicos para esa creación y el reconocimiento. Idem pag.1.305.

52 ¿Existe libertad de creación y establecimiento de universidades en España?, REDA 193, Julio-Septiembre de 2018 págs 14-15.

${ }^{53}$ Idem págs $14-15$ 


\section{D) Puesta en funcionamiento De Titulacion.}

Esta, junto a la cuestión del número de alumnos de nueva entrada, que se analizará más adelante, constituye el eje de desarrollo de una universidad, la cuestión clave, ya que es obvio que el número y la especialidad de las titulaciones universitarias, y el número de alumnos que se puedan admitir, son cuestiones cruciales para el desarrollo del proyecto universitario, que inevitablemente lleva implícito un proyecto empresarial. Por esta misma razón, la puesta en marcha de una titulación está llena de controles y trámites, alguno de ellos formales, pero otros, claramente reiterativos, desproporcionados, e incluso que chocan de lleno contra los requisitos prohibidos antes mencionados.

Para que una universidad pueda poner en marcha una titulación universitaria precisa:

a) En algunas CCAA como Aragón ${ }^{54}$ o el País Vasco ${ }^{55}$ se exige que de modo previo al inicio del proceso de verificación las Universidades obtengan un visto bueno de la consejería competente, cuyos criterios se analizarán más adelante. En otras CCAA, como en Cantabria, y además desde hace muy poco, ${ }^{56}$ se obliga a informar de las titulaciones que se pretenden verificar, remitiendo la misma información que se haya enviado al Consejo de Universidades (en adelante CU).

b) Remisión del título una vez elaborado al CU para una comprobación inicial. ${ }^{57}$

\footnotetext{
${ }^{54}$ Art. 5 de la ORDEN IIU/969/2017, de 23 de junio, por la que se regula el procedimiento de implantación, seguimiento, modificación, renovación de la acreditación y supresión de enseñanzas universitarias oficiales en la Comunidad Autónoma de Aragón ( BOA 13-072017)

${ }^{55}$ Art. 111.2.d) Ley 3/2004, de 25 de febrero, del Sistema Universitario Vasco

${ }^{56}$ Decreto 27/2019, de 14 de marzo, de ordenación de las enseñanzas universitarias oficiales en el ámbito de la Comunidad Autónoma de Cantabria. (Boletín Oficial de Cantabria, de 21-03-2019)

${ }^{57}$ Arts. 24 y 25.1 del Real Decreto 1393/2007, de 29 de octubre, por el que se establece la ordenación de las enseñanzas universitarias oficiales
} 
c) Informe de evaluación de ANECA o la agencia autonómica correspondiente. $^{58}$

d) En caso de que el anterior informe sea positivo, el CU realizará una nueva comprobación, totalmente redundante, ${ }^{59} \mathrm{y}$ dictara resolución de verificación. En caso de ser la resolución negativa, se regula bastante defectuosamente por cierto-, un sistema de alegaciones y recursos previos al contencioso administrativo, en el que además el silencio administrativo se considera negativo. ${ }^{60}$

e) Declaración de la oficialidad del Título por el Gobierno de la Nación. ${ }^{61}$

f) Inscripción en el Registro de Universidades Centros y Título, RUCT. $^{62}$

g) Publicación de los títulos en el Boletín Oficial de la CA y en el BOE. $^{63}$

h) Autorización del Gobierno Autonómico. El art. 35. 2 y 3 de la LOU regulan esta cuestión de manera que deja abierta la posibilidad de que esta autorización pueda ser tanto anterior como posterior a la verificación del Consejo de Universidades. ${ }^{64}$

${ }^{58}$ Art. 25 apartados 2 a 6 del RD 1393/2007.

${ }^{59}$ Art. 25. 7 del RD 1393/20077. Una vez recibido por el Consejo de Universidades el informe favorable, éste comprobará la denominación propuesta para el título, su coherencia con el plan de estudios...

${ }^{60}$ Art. 25 apartados 7 a 11 del RD 1393/2007

${ }^{61}$ Art. 35.3 de la LOU y 261 del RD 1393/2007.

${ }^{62}$ Art. 35.3 de la LOU y Art. $2612^{\circ}$ inciso del RD 1393/2007.

${ }^{63}$ Art. 35.4 de la LOU y Art. 263 del RD 1393/2007.

${ }^{64} 2$. Para impartir enseñanzas oficiales y expedir los correspondientes títulos oficiales, con validez en todo el territorio nacional, las universidades deberán poseer la autorización pertinente de la Comunidad Autónoma, según lo dispuesto en la legislación de la misma y lo previsto en el artículo 8 de esta Ley.

3. Tras la autorización de la Comunidad Autónoma y la verificación del plan de estudios que otorgue el Consejo de Universidades, el Gobierno establecerá el carácter oficial del título y ordenará su inscripción en el Registro de universidades, centros y títulos. 


\section{E) MÁS AUTORIZACIONES NECESARIAS.}

a) Centros propios e Institutos Universitarios de Investigación. ${ }^{65}$

b) Centros adscritos. Según el art. 11 de la LOU la competencia es de la CA afectada, y si Universidad y Centro Adscrito están en distintas CCAA, entonces se requiere una autorización doble.

c) Renovación de la acreditación de los títulos. A modo de nueva verificación para el mantenimiento de la oficialidad de los títulos; el art. 24 y 27 bis del RD 1393/2007 regulan el llamado procedimiento de acreditación de todos los títulos universitarios oficiales.

Pero todavía nos quedan muchas cuestiones que analizar que forman parte de esta malla de autorizaciones regulada en el derecho universitario español, ya que debemos de hablar de las "interesadas" limitaciones al crecimiento de las universidades que se basan en criterios prohibidos, del etéreo principio de programación universitaria, de la sorprendente declaración de centralidad de determinada universidad pública, de la disparatada prohibición de duplicidad de titulaciones en algunas regiones, y de las injustas discriminaciones en la CA de Valencia las universidades privadas y sus alumnos, en materia de becas y prácticas hospitalarias, pero, en cualquier caso, de la relación de autorizaciones hasta ahora vista, ya podríamos ir diciendo, que este conjunto de trabas autorizatorias, muy difícilmente pasarían el examen de los principios antes mencionadas: simplificación de cargas administrativas, subsidiariedad del principio de autorización, y proporcionalidad de las medidas autorizatorias, o el de ventanilla única.

\footnotetext{
${ }^{65}$ La LOU exigía esta autorización autonómica tanto en el 8.2 para los centros propios, como en el 10 para los Institutos Universitarios de Investigación que remitían al 8.2, sin embargo, la Sentencia del TC 26/2016, de 18 de febrero, declara inconstitucional y nulo el apartado 2 del art.8, en los términos del fj 5.c), en la redacción dada por el art. 6.2 del Real Decreto-ley 14/2012, de 20 de abril, eso si por razones distintas a las apuntadas en este artículo. En cualquier caso, normas semejantes a esta se mantienen en las legislaciones autonómicas.
} 


\section{F) MODIFICACION DE LOS PLANES DE ESTUDiO.}

Mención especial, por sus efectos limitativos merece la regulación de la modificación de los planes de estudio, y en particular el relativo a la admisión al alza de los alumnos de nueva entrada, dado que tal y como está establecida, no tanto en las normas administrativas como en los protocolos, e incluso en las aplicaciones informáticas de las Agencias de Calidad Universitaria, resulta del todo dañina para las universidades, y puede hacerles perder de modo totalmente injusto, una parte importante de sus potenciales ingresos.

El análisis es el siguiente: el número de plazas de alumnos de nuevo ingreso es un elemento de los que debe figurar en las memorias de verificación de los planes de estudio que se recoge en el Anexo I del RD 1393/2007, nos corresponde lo primero preguntarnos por cual sería el significado lógico que debería tener esta cifra.

El propio preámbulo del anexo dice que esta memoria constituye un proyecto, y que en caso de cambios, las universidades podrán producir los ajustes necesarios y revisarse los mismos en la fase de acreditación del título, por lo que ya se está dando a entender que existe un lógico margen para que las universidades realicen los ajustes necesario a su situación, que luego podrán revisarse en el marco del proceso de acreditación. Ni en los informes de verificación de la ANECA, ni en las resoluciones de verificación del CU se hace referencia a número de plazas. ${ }^{66}$ Tampoco el número de plazas se recoge en los Boletines Oficiales cuando se publican las resoluciones por las que se establece la oficialidad de determinados títulos, ${ }^{67}$ ni cuando se publica un plan de estudios ${ }^{68}$, ni tampoco cuando se pública una modificación de un plan de estudios ${ }^{69}$. Lo lógico entonces es pensar que la constancia del dato del número de alumnos de nueva entrada, es sólo una referencia para medir si son correctos los recursos humanos y materiales considerados - elementos

\footnotetext{
${ }^{66}$ Por ejemplo, Grado en Derecho por la Universidad San Pablo CEU en 2009. https://srv.aneca.es/ListadoTitulos/sites/default/files/informes/verificacion/InformeFinal_45 7-2008.pdf

${ }^{67} \mathrm{https}: / /$ www.boe.es/buscar/doc.php?id=BOE-A-2018-17518

${ }^{68} \mathrm{https} / / /$ www.boe.es/buscar/doc.php?id=BOE-A-2018-17765

${ }^{69} \mathrm{https}: / /$ www.boe.es/buscar/doc.php?id=BOE-A-2018-17873
} 
6 y 7 de la memoria - en este proyecto de plan de estudios, y título. Deberíamos entender que se han considerado adecuados cuando haya obtenido un informe positivo el plan de estudios, y se haya verificado el título, y por lo tanto, las variaciones realizadas, y los ajustes correspondientes, deberían justificarse en la fase de la acreditación de los títulos. Esta es la interpretación que también se deduce de la guía de apoyo para elaborar las memorias verifica que está publica en la página web de la ANECA, En concreto de la página $12,{ }^{70} \mathrm{y}$ de la plantilla para la evaluación por parte de la ANECA de estos mismos títulos, página $4 .^{71}$ Así las cosas, si una universidad - en particular las privadas- decidieran admitir a más alumnos de los consignados en la memoria de verificación, lo lógico es que ampliara los recursos humanos y materiales proporcionales a este incremento, y lo justificara en el momento de la acreditación. Y esto debería ser especialmente así en el caso de las universidades de titularidad privada.

Lo que sucede es que en la práctica las administraciones y las agencias de calidad están considerando - erróneamente por no decir abusivamente - , esta cifra de alumnos que constan en la memorias de verificación como una especie de "autorización", y la mayoría de las universidades acaban aquietándose a este criterio sin rechistar, y no se atreven a admitir a más alumnos hasta contar con todas las "bendiciones" administrativas, como si se tratará de un centro de educación concertado; lo que les puede hacer perder muchas oportunidades de negocio. Aunque también es cierto que esto se deriva de la ambigüedad - quizás calculada - con la que está diseñado el proceso de cambio de los planes de estudio, y que trataremos de explicar.

Según el art. 28 del RD 1393/2007, sólo las modificaciones que afecten al contenido de los asientos registrales relativos a títulos oficiales inscritos en el RUCT ( Registro de Universidades, Centros y Títulos), deben volver a pasar por la ANECA o agencias autonómicas, y Consejo de Universidades, pero lo cierto - y aquí es donde comienza la ambigüedad -, la norma que regula el RUCT, el Real Decreto 1509/2008, de 12 de septiembre, en su artículo 15, a la hora de establecer los asientos registrales relativos a los

\footnotetext{
${ }^{70}$ file://Users/fernandolostaocrespo/Downloads/verifica_gm_guia_V05.pdf

${ }^{71} \mathrm{file} / / / /$ Users/fernandolostaocrespo/Downloads/verifica_plantilla_v01_111107.pdf
} 
títulos de Grado recoge dos categorías, los fundamentales y los complementarios, y el dato relativo a la cifra de alumnos de nueva entrada, figura precisamente entre los complementarios, y de hecho no se puede consultar en el RUCT. ${ }^{72}$ Como se ha dicho, ni en los boletines oficiales que declaran la oficialidad del título, ni en los que publican los planes de estudio, ni en los que publican sus modificaciones, se recoge el número de plazas. Véase por ejemplo el informe de la ANECA que aprueba en el 2014 el plan de estudios de medicina por la USP CEU, ${ }^{73}$ o el de Derecho de 2018, en el que actuaba ya la Fundación Madrid $+\mathrm{d} .{ }^{74}$ Sin embargo, la aplicación informática de la ANECA que regula el procedimiento de modificación, sí que incluye el número de plazas de nuevo ingreso como un elemento sobre el que informar, extralimitándose claramente de sus funciones. Además, muchas CCAA, sin tener cobertura legal suficiente para ello, quieren controlar del modo previo la ampliación de plazas.

En la CA de Madrid desde el año 2014 la Fundación Madrid $+d^{75}$ tiene asumidas -entre otras- las competencias de verificación, modificación y acreditación. En el protocolo elaborado para la verificación y modificación de los planes de estudio no se hacen distinciones entre tipos de modificaciones, fundamentales y complementarias, y dar por hecho que las modificaciones de plazas si deben pasar por este procedimiento, pág. $52^{76}$. Todo ello, sin que dicha disposición tenga amparo legal en la vigente legislación Madrileña de Universidades, ya que la Ley 4/1998, de 8 de abril, de Coordinación Universitaria de la CA de Madrid, nada dice sobre este tema.

Los protocolos de la ANECA y de las Agencias de Calidad de las CCAA, como tipo de normas de rango menor categorizadas como "soft law" o derecho

\footnotetext{
${ }^{72} \mathrm{https}$ ://www.educacion.gob.es/ruct/estudio.action? codigoCiclo=SC\&codigoTipo=G\&Codig oEstudio $=2500609$ \&actual $=$ estudios

${ }^{73} \mathrm{https}: / /$ srv.aneca.es/ListadoTitulos/sites/default/files/informes/modificaciones/InformeFinal 2_2502164_2014.pdf

${ }^{74} \mathrm{http}$ //www.madrimasd.org/uploads/acreditacion/doc/informefinal_10134_2018.pdf

75 DECRETO 63/2014, de 29 de mayo, por el que se designa a la Fundación para el Conocimiento Madrimas $+\mathrm{d}$ como órgano de evaluación en el ámbito universitario de la Comunidad de Madrid

76 hhttps://www.madrimasd.org/uploads/documents/protocolo_verificacion_titulos_grado_y_ master_0.pdf
} 
blando, han sido analizados por José María Rodriguez de Santiago ${ }^{77}$, quien dice de ellas que no son vinculantes, es decir que no son directamente utilizables por un órgano judicial para declarar la invalidez de la actuación administrativa que (solo) contravenga el soft law. En concreto Rodríguez de Santiago analiza como los protocolos de la ANECA han frustrado la intención que pretendía la reforma de la comisiones de evaluación que se operó el Real Decreto 415/2015, de 29 de mayo, por el que se modifica el Real Decreto 1312/2007, por el que se establece la acreditación nacional para el acceso a los cuerpos docentes universitarios. Esta reforma pretendió pasar de un sistema de evaluación basada en criterios de cantidad, a otro basado en criterios de calidad, y en su opinión, los protocolos de la ANECA han frustrado este cambio, y han provocados que estas comisiones de evaluación vuelva a los criterios anteriores.

Algo parecido podríamos decir del caso analizado de la modificación de planes de estudio en el aspecto relativo a los alumnos de nueva entrada. De la normativa analizada no se desprende, o por lo menos hay serias dudas, que sea necesario que un incremento en el número de alumnos de nueva entrada requiriese un nuevo paso por la ANECA - menos todavía se deprende de la naturaleza económica de los servicios educativos que se prestan -, sin embargo los protocolos de las agencias, y las ijaplicaciones informáticas!!, que ni siquiera se podría decir de las mismas que tengan la categoría de este derecho blando, establecen de modo totalmente tajante que sí que es necesario volver a pasar por las agencias a través del procedimiento denominado coloquialmente como "modifica".

La CA de Aragón todavía es más intervencionista en este campo, ${ }^{78}$ primero, porque de modo previo a la verificación del título, es decir por encima de las exigencias de la ANECA, solicita una memoria en que entre otra muchas cosas, debe realizarse una estimación de la demanda ${ }^{79}$, y segundo, porque en

${ }^{77}$ El "soft law" de la ANECA y los nuevos criterios de 2017 para la Acreditación como catedrático o profesor titular. Homenaje al profesor Menéndez Rexach. Aranzadi.

${ }^{78}$ Lo hace, entre otros instrumentos, a través de la ORDEN IIU/969/2017, de 23 de junio por la que se regula el procedimiento de implantación, seguimiento, modificación, renovación de la acreditación y supresión de enseñanzas universitarias oficiales en la Comunidad Autónoma de Aragón.

${ }^{79}$ Información social sobre la previsión de matrícula de nuevo ingreso; justificación de la oferta de plazas; respuesta a las necesidades formativas y científicas del Sistema Universi- 
los supuestos de modificación de un plan de estudios también debe de pedirse una autorización previa a la CA.

Lo cierto es que, con independencia de que podamos considerar o no, que la modificación de aquellos elementos que constituyen los asientos registrales complementarios de los títulos universitarios de grado, deba ser objeto o no de informe previo de la ANECA, por tener un carácter de asiento complementario y no fundamental, tanto la propia ANECA, como las CCAA, que son además las que financian a las universidades públicas, se han dotado de una serie de instrumentos para controlar el incremento de plazas en las universidades, y esto debe considerarse totalmente ilegal en relación a los servicios educativos privados, desde la perspectiva de una normativa de rango superior como es la que regula la prestación de servicios de naturaleza económica en el mercado interior europeo. Tener que someter a estos trámites administrativos autorizatorios el incremento de plazas de nueva entrada, en relación a las consignadas en la memoria de verificación, puede suponer la pérdida de un tiempo precioso, en el mejor de los casos no menos de un año de trámites administrativos, y con ello la perdida de la matrícula de unos alumnos, no sólo de un curso concreto, sino de los 4 o 5 de la carrera correspondiente. Parece que este caso debería ser claramente uno de aquellos en los que debería bastar con una mera comunicación previa, justificando la aplicación de mayores recursos materiales y humanos proporcionales a este incremento de plazas, y en todo caso procediendo a posteriori a los trámites correspondientes en las agencias de calidad y gobiernos autonómicos.

\section{REQUISITOS PROHIBIDOS EN LA NORMATIVA AUTÓMICA.}

Corresponde ahora analizar una serie de normas autonómicas que chocan de modo frontal con la legislación reguladora de la prestación de servicios económicos.

tario de Aragón; compatibilidad con la oferta existente; posibilidades de inserción laboral. Art. $53^{\circ} \mathrm{b} 2^{\circ}$ 


\section{A) DE NATURALEZA ECONOMICA.}

Recordemos que el art. 10 e) de la LAAS y el 14 de la Directiva de Servicios, prohíben el que se supedite el acceso a actividades de servicio a la superación de una prueba de naturaleza económica, de mercado o de programación $^{80}$; veamos que se desprende de legislación de algunas CCAA que se han analizado:

En Aragón la ORDEN IIU/969/2017, exige para la obtención del informe de adecuación a la programación universitaria de Aragón, que es requisito teóricamente previo al proceso de homologación de los planes de estudio oficiales, los siguientes documentos:

- Información social sobre la previsión de matrícula de nuevo ingreso;

- justificación de la oferta de plazas;

- compatibilidad con la oferta existente;

- los estudios económicos básicos que aseguren la viabilidad del proyecto de implantación de la enseñanza.

Así mismo, el Acuerdo del Gobierno de Aragón de 27 de octubre de 2015, en su artículo tercero f) exige que toda propuesta de implantación de títulos oficiales, vaya acompañada, entre otros muchos documentos, por un plan de viabilidad y de cierre.

En Cantabria, el reciente Decreto 27/2019, al regular en el artículo $4^{\circ}$ los criterios para la implantación de las enseñanzas universitarias oficiales, exige la acreditación de la existencia de una demanda real, tanto por parte de la sociedad como de los/las potenciales estudiantes, demanda que deberá fundamentarse adecuadamente en estudios y referentes externos. Y dentro de

${ }^{80}$ e) Requisitos de naturaleza económica que supediten la concesión de la autorización a la prueba de la existencia de una necesidad económica o de una demanda en el mercado, a que se evalúen los efectos económicos, posibles o reales, de la actividad o a que se haga una apreciación de si la actividad se ajusta a los objetivos de programación económica fijados por la autoridad competente o a que se comercialicen productos o servicios de un tipo o procedencia determinada. Las razones imperiosas de interés general que se invoquen no podrán encubrir requisitos de planificación económica 
los apartados de la Memoria justificativa (artículo 14.4), exigen también realizar las previsiones de matrícula teniendo en cuenta el análisis de la demanda real de los estudios propuestos por parte de potenciales estudiantes y de la sociedad.

En el País Vasco, el Decreto 11/2009, de 20 de enero, de implantación y supresión de las enseñanzas universitarias oficiales conducentes a la obtención de los títulos de Grado, Master y Doctorado, en su artículo 3, exige que las propuestas de implantación de enseñanzas universitarias oficiales de Grado, Master y Doctorado habrán de tener en cuenta la existencia de una demanda real, tanto por parte de la sociedad como de los estudiantes; demanda que deberá fundamentarse en estudios y avales externos, aunque también dice que, se analizarán de forma especial aquellas titulaciones que aun teniendo poca demanda son necesarias para responder a las necesidades de la sociedad vasca.

En Valencia La Orden 86/2010, de 15 de noviembre, de la Conselleria de Educación ${ }^{81}$, exige en su artículo 3.2 acreditar la evolución de la demanda de estudios superiores universitarios, para poder autorizar la implantación.

En Andalucía, el Decreto Legislativo 1/2013, de 8 de enero, por el que se aprueba el Texto Refundido de la Ley Andaluza de Universidades, en el último inciso del apartado $2^{\circ}$ de su artículo 58 exige aportar, entre otros muchos documentos, el estudio de la demanda efectiva de la titulación en el sistema universitario, que incluya los efectos sobre el entorno provincial y andaluz y las posibilidades de inserción laboral de los egresados.

\section{B) Programacion UNIVERSITARIA}

Se trata este de un término frecuentemente mencionado, pero pocas veces concretado, que encierra además un potencial peligro ensimismo si, por ejemplo, se pretende someter la posible implantación de una carrera a los criterios contenidos en la misma. Dada la naturaleza de los derechos en juego, en caso de existir la planificación como tal, no podría tener nunca el

${ }^{81}$ por la que se establece el procedimiento para la implantación de enseñanzas universitarias oficiales de grado, máster y doctorado en las universidades de la Comunitat Valenciana 
mismo efecto en relación a los servicios prestados por la universidad pública que por la privada; en el primer caso podría tener un carácter meramente imperativo, pero en el segundo meramente orientativo o indicador de oportunidades. No olvidemos que la normativa que acabamos de analizar en el apartado anterior, prescribe que las razones imperiosas de interés general que se puedan invocar para justificar un sistema autorizatorio, no podrán encubrir requisitos de planificación económica

La CE utiliza la expresión programación general de la enseñanza en el 27.5 como mecanismo teórico a utilizar por los poderes públicos para hacer efectivo el derecho de todos a la educación. Como es bien sabido la realidad, nos ha llevado a que el campo de la educación haya sido objeto de una enorme normativización, tanto estatal como autonómica, con multitud de cambios dependiendo de los colores de los gobiernos.

En la LOU la programación general de la enseñanza es una de las competencias de la Conferencia General de Política Universitaria (art. 27 bis 1 b), que debe emplearse para la elaboración de los informes preceptivos previos a la creación de una universidad pública (art. 4.2), o al reconocimiento de una privada (art. 4.5), pero el caso es que como tal no existe. Es frecuente en la normativa universitaria autonómica ver referencias a este concepto de programación, pero en la mayoría de las ocasiones lo que se ha desarrollado ha sido simplemente unos criterios conforme a los cuales se debería haber elaborado esta. Repasaremos alguna de estas normativas regionales.

En Aragón el art. 5 de la Ley 5/2005 de Ordenación del Sistema Universitario de Aragón - LOSUA-, define la programación universitaria como el conjunto de disposiciones y decisiones articuladas sistemáticamente que tiene como objeto la planificación a medio y largo plazo de la actividad de enseñanza universitaria desarrollada en Aragón, y ese mismos artículo establece los criterios conforme a los cuales debe elaborarse la misma. ${ }^{82}$ Estos

\footnotetext{
82 a) El grado de demanda de los diferentes estudios y las necesidades de la sociedad en educación universitaria.

b) El equilibrio territorial, en un marco de eficiencia en la utilización de los medios materiales y de los recursos humanos del sistema universitario de Aragón, y los costes económicos y su financiación.
} 
criterios son desarrollados por una norma de rango menor que hemos mencionado con anterioridad, el Acuerdo de 27 de octubre de $2015^{83}$. En cambio, lo que sí que existe dentro de estos criterios, es la prohibición de duplicidad de titulaciones, de la que hablaremos un poco más adelante.

En Valencia se utiliza el término planificación regulado en el art. 7 de la Ley 4/2007, de Coordinación del Sistema Universitario Valenciano, en relación a la creación y reconocimiento de centros docentes en universidades públicas y privadas, respectivamente, y el término programación en el art. 31 , en relación a la aprobación de enseñanzas; sin embargo, ni programación ni planificación se han plasmado en nada concreto.

En Andalucía el art. 57 de la Ley Andaluza de Universidades, condiciona la aprobación de nuevas titulaciones a objetivos y criterios establecidos en la programación universitaria de Andalucía, programación que es descrita en el art. 70 de la misma norma como el instrumento de planificación, coordinación y ordenación del servicio público de educación superior universitaria, sin embargo tampoco está programación se ha concretado en nada.

En Cantabria, el art. 3 del Decreto 27/2019, de 14 de marzo, utiliza el termino alternativo de planificación, que tiene una connotación claramente más imperativa, y que tendrá por objeto: la mejora de la calidad de la docencia, investigación y gestión, con pleno respeto a la autonomía universitaria, logrando que el sistema universitario cántabro sea competitivo a nivel nacional e internacional. También se aprovecha este artículo para en su párrafo $3^{\circ}$ prohibir las repeticiones no justificadas de titulaciones.

En Castilla y León el art. 9 de la Ley 3/2003, de 28 de marzo, de Universidades, regula la naturaleza y criterios conforme a los cuales deba ser aprobada la programación universitaria, y el art. 15 establece que el desarrollo de centros y enseñanzas deba estar contenido en dicha programación,

c) La especialización y diversificación universitaria en un contexto de cooperación interuniversitaria.

d) La actividad de investigación que en el sistema universitario de Aragón vaya a desarrollarse, teniendo en cuenta, a esos efectos, lo que se deduzca del plan específico vigente en cada momento.

${ }^{83}$ Esta Orden establece objetivos, criterios y requisitos que guiarán la programación de las enseñanzas universitarias para el periodo 2016-2019, pero el caso es que la programación como tal no existe. 
y también menciona la necesidad de dotarse de un Mapa de Titulaciones. Sin embargo, esta CA ha ido más lejos que otras, ya que ha concretado un mapa de titulaciones, y no se ha limitado a definiciones, criterios o procedimientos, y además lo ha hecho por la vía del acuerdo, y no de la norma, aunque se haya hecho de modo separado universidades públicas y privadas, e interviniendo en ambas el Consejero de Educación. Ambos acuerdos se firmaron el 27 de julio de 2016 y abarcaban el periodo 2016-2019. ${ }^{84}$

El plan universitario del País Vasco está recogido en el art. $67^{85}$ de ley $3 / 2004$, pero su alcance es mucho mayor ya que incluye la financiación, a través del instrumento del contrato programa, de las 3 universidades del País Vasco, incluidas las 2 privadas - Deusto y la Mondragón -, aunque con cuantías mucho menores que la pública. En la actualidad está fase de elaboración el $4^{\circ}$ programa, el del periodo $2019-2022 .{ }^{86}$

De las CCAA analizadas, con la excepción de Castilla León que ha plasmado en forma de acuerdo un mapa de titulaciones, y la notable del País Vasco, que desarrolla unos planes muy completos, en la que se incluye la financiación vía contrato programa de todas sus universidades, la regulación de la programación universitaria se limita a definir el concepto, y a establecer una serie de criterios, por lo general muy abstractos, para su elaboración, sin que ello se plasme en nada en concreto, aunque si sometiendo a dicha "teórica" programación, la autorización para la puesta en marcha de nuevas titulaciones. Todo ello puede suponer una doble irregularidad, primero por el

84 https://diarium.usal.es/ccoo/2016/07/28/mapa-de-titulaciones-universitarias-de-castilla-yleon/

85 1. El Plan Universitario es el instrumento específico aprobado por el Gobierno para la ordenación del sistema universitario vasco.

2. El Plan Universitario tendrá una vigencia de cuatro años, y evaluará la situación de la enseñanza universitaria, determinará sus necesidades y establecerá los objetivos y prioridades para su periodo de vigencia, así como las necesidades de financiación y los ingresos previsibles, garantizando a la Universidad del País Vasco un modelo de financiación suficiente para el cumplimiento de sus finalidades y la mejora de la calidad.

3. El Gobierno podrá determinar áreas o materias de investigación preferente por su interés estratégico para el País Vasco o por razones de interés científico, artístico o social, que serán dotadas mediante contratos-programa específicos

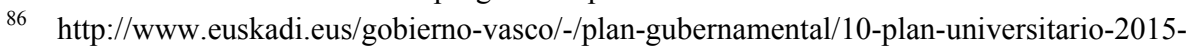
2018/ 
hecho mismo de someter la autorización de la prestación de un servicio universitario económico a lo previsto en una determinada programación, y segundo por la inseguridad jurídica que crea la falta de concreción de dichas programaciones.

\section{C) PROHIBICIÓN ABSOLUTA DE DUPLICIDAD DE TITULACIONES, EN PARTICULAR EL CASO DE ARAGON.}

Un avance en esta escalada de limitaciones, lo constituye la prohibición de duplicación de titulaciones universitarias, que es total, aunque parcial territorialmente, en Aragón, y relativa en País Vasco y Cantabria, puesto que admite excepciones.

En Aragón está establecida la prohibición absoluta de duplicidad de titulaciones que estén previamente implantadas en los llamados campus periféricos de la Universidad de Zaragoza, es decir Huesca, Teruel, y el centro adscrito de la localidad de La Almunia de Doña Godina, provincia de Zaragoza. Esta norma parece que afectaría sobre todo a la única alternativa universitaria que existe en Aragón, la Universidad "privada" San Jorge, pero en realidad también lo hace a la propia Universidad de Zaragoza, ya que esta no puede poner en marcha en su campus de la ciudad de Zaragoza, titulaciones previamente implantadas en los llamados campus periféricos. ${ }^{87}$ Con independencia del juicio político que pudiera merecer el intentar el desarrollo de un ámbito territorial de esta manera, lo cierto es que carece de toda lógica, desde la perspectiva del ejercicio de derechos constitucionales como son la libertad de creación de centros docentes ( art. 27.6 CTE), o la libertad de empresa (art. $38 \mathrm{CTE}$ ), y por supuesto desde la óptica desde la que estamos realizando este trabajo, la de las condiciones para la prestación de servicios

\footnotetext{
${ }^{87}$ Por ello, la ciudad de Zaragoza que cuenta aproximadamente con 700.000 habitantes, no puede implantar ni en el campus privado de la Universidad San Jorge, ni en el público de la Universidad de Zaragoza, titulaciones como Bellas Artes o Psicología - que por cierto estaban en el anexo de titulaciones de la ley 1/2005 de 24 de febrero, de las Cortes de Aragón, de reconocimiento de la Universidad San Jorge previamente implantadas en el campus de Teruel, u odontología implantada en el del Huesca.
} 
de naturaleza económica, la prohibición total de competencia universitaria en un ámbito territorial.

La normativa que prohíbe esta duplicidad está recogida en el art. 5 de Ley 5/2005, de la LOSUA, y el Art. tercero a) del Acuerdo de 27 de octubre de 2015 del Gobierno de Aragón, además extrañamente, la regulación de esta prohibición comenzó primero en la norma administrativa inferior, y luego se elevó a la de rango legal; como quiera que la CNMC haciendo uso de las atribuciones que le concede el art. 27 de la LEGUM, recurrió la citada Orden, impugnándola en la vía contenciosa administrativa en la Audiencia Nacional, el Gobierno Aragonés llevo a las Cortes Regionales la modificación de la LOSUA, para que se recogiera también dicha prohibición, y poder así escapar de la acción de la CNMC. Dicha modificación fue aprobada por las Cortes Aragonesas, y entró en vigor el 4 de febrero de 2016, pero quizás con lo que no se contaba era con que el Gobierno en funciones de presidente Rajoy llevaría ante el TC dicha reforma ${ }^{88}$. Ambos recursos se encuentran en la actualidad pendientes de sentencia.

Como se ha dicho, la CMCN emitió el 14 de julio de 2016 un informe en relación a este conflicto ${ }^{89}$, en el que además de pronunciarse en términos generales sobre la falta de competitividad intrínseca del sistema universitario español, se abordó la cuestión de la prohibición de solapamiento de titulaciones. ${ }^{90}$ Yendo al meollo de la cuestión, el informe considera que esta limitación debe ser considerada como una restricción muy severa de la competencia, que refuerza el poder de mercado de la Universidad de Zaragoza, al limitar la entrada, la expansión y

\footnotetext{
${ }^{88}$ El Pleno del Tribunal Constitucional, por Providencia de 15 de noviembre de 2016, acordó admitir a trámite el recurso de inconstitucionalidad número 5724-2016, contra el inciso final del apartado Uno del artículo 49 de la Ley 2/2016, de 28 de enero, de Medidas Fiscales y Administrativas de la Comunidad Autónoma de Aragón, que modifica el artículo 5 de la Ley 5/2005, de 14 de junio, de Ordenación del Sistema Universitario de Aragón

${ }^{89}$ Informe económico sobre el acuerdo de 27 de octubre de 2015 del gobierno de Aragón sobre los objetivos, criterios y requisitos de las enseñanzas universitarias oficiales en la comunidad autónoma de Aragón para el periodo 2016-2019 - um/001/16

${ }^{90} \mathrm{El}$ informe hace un estudio de la evolución del mercado universitario aragonés desde la aparición de las USJ en el año 2005, y del efecto positivo de la entrada de un nuevo operador en este sector, que progresivamente ha ido ganando cuotas de mercado hasta alcanzar un 6,8 del total y cerca del $20 \%$ en las titulaciones concurrentes.
} 
la capacidad de competir de operadores potenciales y efectivos, y en concreto, de la Universidad de San Jorge, que constituye la única universidad que compite con la de Zaragoza en Aragón; la restricción protege a la Universidad de Zaragoza frente a la entrada y la competencia de operadores alternativos en las enseñanzas que ya imparte. Sus efectos negativos son numerosos. Un primer efecto negativo es la disminución de la motivación que va a tener el operador al que le es otorgado el monopolio territorial, en entrar en procesos continuos de mejora de calidad y eficiencia.

Pero hay otro segundo efecto, que es igualmente negativo, que en realidad puede tener un efecto boomerang, ya que ante esta reducción de titulaciones en determinadas ciudades, muchos potenciales alumnos pueden decidir abandonar el territorio universitario aragonés, e ir a estudiar a otras localidades donde se ofrezcan las titulaciones de su preferencia. Es cierto que esta medida protectora de los campus de periféricos obedece a una razón ajena a la esencia de lo universitario, ya que se pretender utilizar la universidad para vertebrar el territorio, pero siendo noble la razón - continua el informe-, "se convierte en ilegítima cuando lleva aparejada la restricción ilegítima de los competidores. Las medidas de promoción, justificadas en sí mismas, no tienen por qué llevar consigo la restricción del competidor". Es como si la instalación de Dinópolis en Teruel llevara aparejada la prohibición de que un operador privado instalará un Dinópolis "2" en Calamocha, Alcañiz o Albarracín, y además, puede volverse en su contra la medida, ya que muchos alumnos que hubieran querido estudiar Bellas Artes o Psicología en Zaragoza, ya sea en el campus de la UZ o ya en el de la USJ, puede preferir irse a Madrid, Barcelona o Valencia, antes que ir a Teruel.

Aunque el tema está pendientes de dos resoluciones judiciales que pueden arrojar mucha luz sobre la cuestión, lo cierto es que un antecedente de las normas actuales ha dado lugar a una sentencia del TSJ de Aragón que ha reforzado la línea marcada por la CNMC. Antes de las actuales prohibiciones de duplicidad, existió una Orden del año 2012 del Gobierno PP-PAR, que fue la primera que introdujo esta prohibición de duplicidad. Fue la Orden de 28 de junio de $2012^{91}$, la que dio este primer paso en el vacío, que

\footnotetext{
${ }^{91}$ de la Consejera de Educación, Universidad, Cultura y Deporte, por la que se publica el
} 
llegó más allá de lo que había llegado el anterior Gobierno autonómico PSOE-PAR, prohibiendo directamente en su artículo 2 la simultaneidad de titulaciones previamente implantadas en los citado campus periféricos de la UNIZAR. Esta norma fue objeto de denuncia ante el CNMC por la USJ, y dio lugar al informe de la Secretaria del Consejo para la Unidad de Mercado - SECUM- de 25 de junio de 2014, que comenzaba considerando que debían incluirse las actividades de las universidades privadas en el ámbito de la LEGUM, dado que, como sabemos, la prestación de servicios educativos pagados constituyen una actividad económica.

Este informe de 2014, también cita el manual sobre la transposición de la Directiva de Servicios, 2006/123/CE, elaborado por la Comisión, que insiste también en la sujeción de los servicios de educación pagados a la Directiva de Servicios. En relación a la cuestión de la prohibición de duplicidad de titulaciones, entiende este informe que supone una prohibición que podría contravenir el artículo 5 de la LEGUM por ser innecesaria y desproporcionada. ${ }^{92}$ Pero esta inicial prohibición aragonesa de duplicidad de titulaciones encontró un hueco de liberalización al final de esta mandato autonómico del PP-PAR, que decidió eliminar esa prohibición ${ }^{93}$, aunque como hemos visto pocos meses después, el nuevo Gobierno autonómico PSOE-CHA, apoyado desde el parlamento por PODEMOS, volvió a establecerla. ${ }^{94}$ Pues bien, di-

Acuerdo de 19 de junio de 2012, del Gobierno de Aragón, por el que se establecen los principios y requisitos que guiarán la programación de las enseñanzas universitarias oficiales en la Comunidad Autónoma de Aragón para el periodo 2012-2015

92 Además, en la medida en que este requisito sea considerado un requisito de oferta podría incluso constituir un requisito prohibido por el mencionado artículo 18.2.g), ya que se impondrían limitaciones geográficas a la oferta por motivos económicos. A este respecto, el artículo 11.1.a) de la Ley 17/2009, aplicable a la prestación de servicios de educación, aclara esta cuestión al permitir con carácter excepcional las restricciones territoriales pero al señalar explícitamente que estas no podrán imponerse por fines económicos (para garantizar la viabilidad económica de determinados prestadores).

${ }^{93}$ Mediante la ORDEN de 16 de febrero de 2015, de la Consejera de Educación, Universidad, Cultura y Deporte, por la que se publica el Acuerdo de 10 de febrero de 2015, del Gobierno de Aragón, se eliminó la prohibición de duplicar titulaciones.

${ }^{94}$ Esta problemática la abordó de un modo más amplio en mi artículo: Restricciones a la competencia en la CA de Aragón, que forma parte del libro La competencia como Motor de 
cho hueco liberalizador dio lugar a que el Gobierno de Aragón autorizara la implantación de los Grados de Educación Infantil y Primaria en la Universidad San Jorge, autorización que fue recurrida por el Ayuntamiento y la Diputación Provincial de Huesca, y que dio lugar a la sentencia antes aludida de la sala de lo CA del TSJ de Aragón de 24 de noviembre de 2017, que rechazó el recurso con este argumento principal:

\begin{abstract}
Objetivamente, y sin ánimo de prejuzgar el resultado en procesos en curso, el mantenimiento de la prohibición de duplicidades en la impartición de titulaciones universitarias, constituye una limitación al ejercicio de una actividad económica (enseñanza universitaria) por terceros operadores. En este sentido, la LEGUM no impide la existencia de limitaciones, como tampoco lo hacía la Ley 17/2009, ni la Directiva de Servicios; lo que se exige es la fundamentación de la restricción que se impone en razones imperiosas de interés general, entre las comprendidas en el artículo 3.11 de la Ley 17/2009, dice el artículo 5.1 de la Ley 20/2013. Y es lo cierto que, en el caso concreto, la Administración no las encuentra, razón por la cual suprime tal prohibición de duplicidades en el Acuerdo impugnado, actuando, por consiguiente de manera ajustada a Derecho.
\end{abstract}

Como hemos indicado, las CCAA del País Vasco y Cantabria se posicionan también en contra de la duplicidad pero lo hace de un modo algo menos tajante dado que permiten excepciones. En el País Vasco, el art. 2.2 del Decreto 11/2009, establece el principio de la no autorización de las titulaciones que repitan lo ya existente, si no se razona debidamente, y en la misma línea el art. 3.3 del Decreto 27/2019 de Cantabria, establece el principio de la complementariedad del sistema universitario cántabro, sin que se produzcan repeticiones no justificadas en base a la demanda social de titulaciones, $n i$ carencias significativas en la oferta. Tampoco parece nada claro que unas normas como estas que establecen la prohibición de la duplicidad como regla general, pasaran el examen de legalidad en cuanto a la necesariedad y proporcionalidad de la medida, y menos el de las razones imperiosas de interés general que las avalen.

Desarrollo Económico de Aragón, dirigido por María del Pilar Canedo Arrillaga. Aranzadi 2018. Pags. 578-604. 


\section{D) LA EXIGENCIA DE UN NUMERO MINIMO DE ALUMNOS.}

Algunas legislaciones autonómicas se han atrevido a regular la necesidad de un número mínimo de alumnos en las titulaciones oficiales, una vez más sin distinguir entre universidades públicas y privadas.

En Aragón la normativa ${ }^{95}$ se limita a decir que en caso de que una titulación de grado pierda en un curso el 50\% de sus alumnos, o en dos consecutivos el 25\%, o una de Master se sitúa por debajo de 10 alumnos, las universidades deberán elaborar un plan de actuación con objeto de proceder a los cambios necesarios que permitan la continuidad de la titulación, su modificación o supresión. El plan, una vez aprobado por la universidad, será remitido a la Agencia de Calidad y Prospectiva Universitaria de Aragón con objeto de que verifique su cumplimiento en el proceso de seguimiento

En Cantabria, el Decreto 27/2019, es más agresivo ya que establece, de nuevo sin distinguir entre universidades públicas y privadas, un número de alumnos mínimo:

- Como estimación de alumnos de nueva entrada, de cara a una posible autorización de puesta en funcionamiento, se establece un mínimo 40 de grado, y 10 en los Masters, salvo excepciones debidamente fundamentadas que acrediten la viabilidad de la enseñanza independientemente del número de alumnos. Art. 5

- Para la renovación de la acreditación, 35 de grado, 10 en los Masters, y en Doctorado se requerirá que el número de tesis leídas sea como mínimo de 4 , y que el programa cuente con un número de doctorandos no inferior a 10.Art. 18

- Como causa de revocación de la autorización de puesta en funcionamiento de los títulos, por haber tenido durante tres años consecutivos, una media inferior a 35 en los grados y 10 en los Masters y Doctorado. Art. 22

Parece evidente que está normativa, aunque no tengan aparejadas una consecuencias concretas en el caso de la aragonesa, y admita excepcio-

\footnotetext{
${ }^{95}$ Artículo tercero B y C del Acuerdo del Gobierno de Aragón de 27 de octubre de 2015.
} 
nes, en cuanto a los alumnos de nueva entrada en la cántabra, al no distinguir entre universidades públicas y privadas, comete una nueva intromisión en los derechos esenciales de la universidades privadas, cuya estructura de costes puede tener los umbrales de rentabilidad en números muy distintos, o que incluso pueden decidir mantener una titulación abierta, a pesar de su no rentabilidad por razones de política o filosofía interna, en la que no debería entrometerse la administración, ya que de otro modo se lesionarían derechos esenciales en el ámbito de la educación y la libertad de empresa, del que es una concreción el derecho a la libre iniciativa económica, recogida en el art. 16 de la LEGUM. Unas medidas como las que se acaba de analizar, tampoco pasarían el test de la necesariedad y proporcionalidad, y menos el de la existencia de una razón imperiosa de interés general. Una universidad privada deber ser completamente libre a la hora de decidir cuándo cierra una titulación, sabiendo que pesa sobre ella la obligación de permitir que todos los alumnos que hayan iniciado sus estudios, los puedan terminar siempre que empleen un nivel de aprovechamiento medio.

También podría valorarse en qué medida esta normativa que entra hasta en el detalle del número mínimo de alumnos, estaría yendo más allá de normativa estatal, como el RD 1393/2007 de Ordenación de las Enseñanzas, el RD 420/215 de Creación y Reconocimiento de Universidades y Centros, o incluso de la propia LOU, que en ningún momento establecen la exigencia de un número mínimo de alumnos, ni para verificar un título oficial, ni para acreditarlo, ni para revocarlo, y por lo tanto, estas normas autonómicas podrían suponer la violación de una normativa de carácter básico, dado que el apartado 30 del 149. 1 de la CTE establece como competencia básica del estado la Regulación de las condiciones de obtención, expedición y homologación de títulos académicos y profesionales y normas básicas para el desarrollo del artículo 27 de la Constitución, a fin de garantizar el cumplimiento de las obligaciones de los poderes públicos en esta materia. 


\section{E) LIMITACIONES ESPECÍFICAS EN LA CA DE VALENCIA.}

La CA de Valencia ha experimentado en los últimos años una fuerte restricción tanto a los derechos de las universidades privadas de la comunidad, como de sus alumnos. La primera de estas limitaciones la constituye la prohibición de realizar prácticas en centros hospitalarios públicos de los alumnos de carreras sanitarias de universidades privadas, y la segunda consiste en el veto a que alumnos de estas universidades puedan acceder a una serie de becas y ayudas establecidas por la propia Generalidad Valenciana.

La prohibición de la realización de prácticas tuvo origen en una reforma de la Ley 10/2014 de Salud de la Comunidad Valenciana, operada por la Ley 8/2018, que reformo el apartado 2 del art. 79 de la anterior para añadir la expresión de "titularidad pública" al término Universidad, con lo que se impedía el que los alumnos de Universidades de titularidad privada pudieran hacer prácticas en hospitales públicos. Esta reforma dió lugar a la denuncia de una serie de convenios existentes entre la Consellería de Salud y las Universidades privadas, en particular la Cardenal Herrera CEU y la Católica de Valencia, y aunque las primeras sentencias recaídas han dado la razón a las Universidades impugnantes, lo cierto es que el TC en una sentencia de 31 de enero de 2019, recurso de inconstitucionalidad 4182-2018, ha venido a zanjar de modo definitivo la cuestión, al declarar inconstitucional y nula, la incorporación de la citada expresión, "titularidad pública", aunque sus razonamientos no se basan tanto en la infracción del principio de igualdad, cuanto por contravenir las competencias exclusivas del Estado en materias de educación y de bases de la sanidad, reconocidas en el art. 149.1 apartados 30 y 16 de la CE, que se concretan en la Ley 14/86, General de Sanidad, y la Ley 44/2003, de Ordenación de las profesiones sanitarias, que no distinguen entre tipos de universidades a los efectos de la realización de prácticas por los alumnos de enseñanzas sanitarias, sea cual sea su nivel.

El veto del acceso de los estudiantes de las universidades privadas a las ayudas y becas establecidas por el propio Gobierno Valenciano, fue recurrido por las propias universidades privadas, aunque sin éxito inicialmente dado que el TSJ de Valencia no las estimó legitimadas de fondo, sin embargo sí que ha estimado los recursos contencioso administrativos de los alum- 
nos afectados por esta normativa, a los que se denegó la concesión de alguna de estas ayudas. Como ejemplo de ello la sentencia de la sala de lo CA del TSJ de Valencia $n^{\circ}$ 132/2019, de 27 de febrero de 2018.

\section{F) OTRAS LIMITACIONES}

Otra limitación a las Universidades privadas en este caso relacionada con el momento de la nacimiento, lo constituye el párrafo $4^{\circ}$ del art. 108 de la Ley 3/2004 del sistema universitario Vasco, que exige a las Universidades no públicas la constitución de un capital o de una garantía financiera no inferior a 3 millones de euros. Este requisito podría considerase tanto contrario a los derechos antes mencionados como la libertad a la creación de centros docentes, de empresa, y de prestación de servicios económicos, por desproporcionados, como infractor de la legislación básica del estado ya que ni la LOU, ni el Real Decreto 420/2015, establecen un requisito semejante a los promotores de universidades privadas.

Por último en este apartado mencionaremos la curiosa declaración de centralidad de la Universidad de Zaragoza que contiene el art. $3^{96}$ de la LOSUA, que aunque no lleve aparejada de inicio ninguna consecuencia concreta, es muy reveladora de la visión con la que se contempla el sistema universitario aragonés, en el que las universidades privadas - de momento sólo existe la Universidad San Jorge -, están llamadas a jugar un papel claramente complementario, y de allí la justificación de los controles a las que se las somete.

\section{CONCLUSIONES.}

Desde la perspectiva de derecho europeo no se puede considerar ilegales las ayudas que recibe el sistema universitario público en España, ya que la edu-

\footnotetext{
${ }^{96}$ La Universidad de Zaragoza constituye el elemento central del sistema universitario de Aragón, por lo que el Gobierno y los Departamentos que se relacionen con ella deberán mantener especiales relaciones de cooperación, con pleno respeto a su autonomía garantizada constitucionalmente.
} 
cación financiada públicamente no tiene la naturaleza de servicio económico, sino de Servicio No Económico de Interés General, que se rige por el principio de solidaridad y no de capitalización, y por lo tanto queda al margen de la aplicación del derecho tendente a fomentar la competencia. Sin embargo, también es cierto que el sistema de financiación de la universidad pública en España, y en general el funcionamiento del sistema universitario en España, adolece de grandes fallos, como son la falta de equidad, claridad, transparencia, rendición de cuentas, competencia interna, y en definitiva de eficacia, y por más que esto se refleje en muchos informes, y en el comentario de muchos expertos, nada parece cambiar. Además, algunas de las prácticas que realizan las universidades públicas sí que podrían considerarse ilícitas por abusivas, dado que entran en competencia tanto con universidades privadas como los otros operadores económicos, en el campo de la formación no oficial o títulos propios, y en el de servicios a las empresas, vía art. 83 de la LOU, sin aclarar convenientemente - al carecer de contabilidad de costes -, si los medios que aplican para conseguir esos ingresos, son los mismos que son financiados por las CCAA para la enseñanza e investigación oficial, o son otros.

Existe una gran segunda desventaja competitiva que sufre la Universidad de titularidad privada, y es el de la limitación de su desarrollo, que se produce de un modo desproporcionado por la existencia de una ingente cantidad de normas, controles y sistemas de autorización, que no se corresponden con la naturaleza de los servicios que presta. Los servicios educativos no subvencionados, tienen naturaleza de servicios económicos, y por lo tanto, en su implantación y desarrollo, en particular en lo que se refiere a la creación de centros, titulaciones y aumento de plazas, no deberían someterse al régimen de autorización como regla, sino más bien como excepción, y además debería en todo caso, justificarse la necesidad y proporcionalidad del procedimiento de autorización, ya que todo lo demás constituiría una limitación injustificada de la competencia.

Esto choca de frente con la realidad de nuestro panorama normativo, en particular con el autonómico, ya que la realidad nos dice que los controles y las autorizaciones no sólo no disminuyen, sino que siguen creciendo. Una gran parte de esta normativa es contraria a legislación reguladora de la pres- 
tación de servicios en el mercado interior europeo, incorporada ya a nuestro derecho interno como derecho nacional, dado que exigen la demostración de una respuesta del mercado, u otra prueba similar de naturaleza económica, siendo que este tipo de pruebas están expresamente prohibidas como requisito para autorizar la prestación de un servicio.

Algunos gobiernos regionales utilizan términos como coordinación, programación, o planificación para justificar normas que sirven para proteger a sus universidades regionales, limitando la capacidad de desarrollo de las privadas, aunque dicha programación en la mayoría de los casos no se haya concretado en nada. Incluso en ocasiones, las prohibiciones no tratan de ser sutiles, y apoyarse en la exigencia de requisitos de viabilidad, necesidad del mercado o empleabilidad, sino que establecen prohibiciones directas sin mayor remordimiento, como pueda ser la prohibición de duplicidad de titulaciones, (Aragón, País Vasco y Cantabria) o la realización de prácticas en hospitales públicos por parte de los alumnos de las universidades privadas ( Valencia), aunque esta última prohibición ya ha sido vencida en el TC.

A pesar de todas estas desventajas, las Universidades privadas siguen ganando cuotas de mercado, y ya se han situado en un $16,5 \%$, por lo que cabría preguntarse, que no harían si el sistema fuera más equilibrado en las condiciones de partida de la lucha competitiva, y además, también nos tendríamos que preguntas, si un entorno competitivo mucho más igualado y exigente, no ayudaría a la propia universidad pública a mejorar, y con ello nuestro sistema nacional de $\mathrm{i}+\mathrm{d}+\mathrm{i}$, y a la competitividad de nuestras empresas, con efectos positivos en toda la sociedad, y por lo tanto en el bien común mismo. 